1 8

\title{
The FLI portion of EWS/FLI contributes a transcriptional regulatory function that is distinct and separable from its DNA-binding function in Ewing sarcoma
}

Megann A. Boone ${ }^{1,2}$, Cenny Taslim², Jesse C. Crow², Julia Selich-Anderson², Iftekhar A.

Showpnil2,3, Benjamin D. Sunkel², Meng Wang ${ }^{2}$, Benjamin Z. Stanton ${ }^{1,2,3,4}$, Emily R.

Theisen ${ }^{1,2,3,4}$, Stephen L. Lessnick ${ }^{1,2,3,4}$

${ }^{1}$ Biomedical Sciences Graduate Program, The Ohio State University, Columbus, $\mathrm{OH}, 43210$, USA

${ }^{2}$ Center for Childhood Cancer and Blood Diseases, Abigail Wexner Research Institute at Nationwide Children's Hospital, Columbus, OH, 43205, USA

${ }^{3}$ Molecular, Cellular, and Developmental Biology Graduate Program, The Ohio State University, Columbus, $\mathrm{OH}, 43210$, USA

${ }^{4}$ Department of Pediatrics, The Ohio State University, Columbus, $\mathrm{OH}, 43210$, USA

To whom correspondence should be addressed:

Stephen L Lessnick, MD, PhD

1 Abigail Wexner Research Institute at Nationwide Children's Hospital, 700 Children's Drive, WA5011, Columbus, OH, 43205, USA;

3 Tel: +1 (614) 355-2633; Fax: +1 (614) 355-2927;

Email: stephen.lessnick@nationwidechildrens.org 


\section{Abstract}

27 Background: Ewing sarcoma is an aggressive bone cancer in children and young adults that contains a pathognomonic chromosomal translocation: $t(11 ; 22)(q 24 ; q 12)$. The encoded protein, EWS/FLI, fuses the low-complexity amino-terminal portion of EWS to the carboxyl-terminus of FLI. The FLI portion contains an ETS DNA-binding domain and adjacent amino- and carboxylregions. Early studies using non-Ewing sarcoma cellular models provided conflicting information on the role of these adjacent regions in the oncogenic function of EWS/FLI. We therefore sought to define the specific contributions of each FLI region to EWS/FLI activity in an appropriate Ewing model, and in doing so, to better understand Ewing sarcoma development mediated by the fusion protein.

Methods: We used a "knock-down/rescue" system to replace endogenous EWS/FLI expression with mutant forms of the protein in Ewing sarcoma cells and tested these for oncogenic transformation using soft-agar colony forming assays. These data were complemented by DNAbinding assays using fluorescence anisotropy, genomic localization assays using CUT\&RUN, transcriptional regulation studies using luciferase reporter assays and RNA-sequencing, as well as chromatin accessibility assays using ATAC-sequencing.

Results: We found that the DNA-binding domain and short flanking regions of FLI were required for oncogenic transformation, gene expression, genomic localization and chromatin accessibility when fused to the amino-terminal EWS-portion from EWS/FLI, but that the remaining regions of FLI were dispensable for these functions. Removal of a carboxyl-terminal alpha-helix from the

47 retained normal DNA binding, genomic localization, and chromatin accessibility, but had significantly restricted transcriptional activity and a near total loss of oncogenic transformational capacity.

Conclusions: The DNA-binding domain and carboxyl-terminal short flanking region of FLI are 
52 sarcoma cellular context. In addition to the well-defined DNA-binding function of FLI, this

53 additional alpha-helix immediately downstream of the DNA-binding domain contributes a

54 previously-undescribed function in gene regulation and oncogenic transformation. Understanding

55 the function of this critical region could provide new therapeutic opportunities to target EWS/FLI

56 in Ewing sarcoma.

57

Keywords: Ewing sarcoma, EWS/FLI, translocation, ETS, structure-function

\section{Background}

61 Ewing sarcoma is a bone-tumor of children and young adults (2). These tumors always contain

62 chromosomal translocations that encode fusions between a member of the FET protein family and one of the ETS transcription factors $(1,3)$. The most common translocation (in $~ 85 \%$ of patients) is the $\mathrm{t}(11 ; 22)(\mathrm{q} 24 ; \mathrm{q} 12)$, which fuses $E W S R 1$ to $F L / 1(1,4,5)$. The EWSR1/FLI1 fusion encodes the EWS/FLI protein $(3,6)$. Multiple studies have demonstrated that EWS/FLI has oncogenic function and serves as the driver oncoprotein in Ewing sarcoma (1, 4, 7). Indeed, EWS/FLI is often the only genetic abnormality in these otherwise "genomically-quiet" tumors (8). Thus, determining the mechanisms underlying the oncogenic function of EWS/FLI is critical to understanding Ewing sarcoma tumorigenesis, identifying new therapeutic approaches for this aggressive disease, and may also shed light on the oncogenic mechanisms of other "ETSassociated" tumors.

EWS/FLI functions as an aberrant transcription factor and dysregulates several thousand genes

74 (9, 10). The intrinsically-disordered low-complexity domain of EWS contributes strong 75 transcriptional activating and repressing functions to the fusion (11-13). The mechanisms by 
77 include the recruitment of epigenetic co-regulators and RNA-polymerase II, perhaps via the

78 formation of transcriptional "hubs" consisting of low-affinity/high-valency interactions, phase-

79 separated droplets, or even polymerized fibrils $(9,14-17)$.

$81 \mathrm{FLI}$ is a member of the ETS family of transcription factors (18-20). The 28 ETS family members

82 in humans are defined by the presence of highly conserved winged helix-turn-helix DNA-binding

83 domains (DBD) (18). The preferred high-affinity (HA) binding sequence for FLI is

84 "ACCGGAAGTG", while other family members bind similar sequences containing a GGA(A/T) core surrounded by additional base pairs $(18,21)$. Structural studies have demonstrated that the third alpha-helix of the FLI DNA-binding domain (part of the winged helix-turn-helix structure)

87 binds in the major groove of DNA $(19,22,23)$. Several ETS family members demonstrate "autoinhibitory" activity in which domains adjacent to the DNA-binding domain reduce the ability of ETS factors to bind DNA (24). However, FLI harbors only minimal autoinhibitory activity ( 2-3 fold reduction in binding affinity) $(24,25)$. In addition to binding classic ETS HA sites, EWS/FLI also binds to microsatellite sequences consisting of multiple "GGAA" tetrameric repeats (26-28). There are thousands of GGAA-microsatellite sequences scattered throughout the human genome, and many of these serve as EWS/FLI-response elements associated with target genes critical for oncogenic transformation in Ewing sarcoma (26-28). The ability of EWS/FLI to regulate target genes through GGAA-microsatellites appears to be a neomorphic function gained by the fusion protein as compared to wild-type FLI. Along with the ETS DNA-binding domain, the FLI

97 portion of the fusion contains additional amino-terminal and carboxyl-terminal regions of uncertain 98 function. The cell of origin of Ewing sarcoma is not known (29). Early studies that analyzed the role of the

101 FLI portion of EWS/FLI used heterologous cell types, such as NIH3T3 murine fibroblasts, with conflicting results (29). For example, expression of wild-type EWS/FLI induces oncogenic 
103

104

105

106

107

108

109

110

111

112

113

114

115

116

117

118

119

120

121

122

123

124

125

126

127

128

transformation of NIH3T3 cells, while expression of an EWS/FLI mutant harboring a complete deletion of the ETS DNA-binding domain did not, demonstrating a critical role for DNA-binding in the function of EWS/FLI (7). In contrast, a later study demonstrated that a partial deletion of the ETS DNA-binding domain (that also disrupted DNA-binding) instead retained the capability of inducing oncogenic transformation of NIH3T3 cells (30). Subsequent studies in patient-derived Ewing sarcoma cells showed that a DNA-binding defective mutant of EWS/FLI was unable to mediate oncogenic transformation in cells, thus proving that DNA-binding is absolutely required for EWS/FLI-mediated transformation in a more relevant Ewing cellular model (13). The carboxylterminal region of FLI (outside of the DNA-binding domain) was also evaluated in the NIH3T3 model and determined to be important for transcriptional control and oncogenic transformation mediated by EWS/FLI, though this has not been reproduced in a Ewing sarcoma model (31). Later work demonstrated that gene expression patterns mediated by EWS/FLI in the NIH3T3 model were drastically different from those in Ewing sarcoma cellular models, suggesting that EWS/FLI may utilize alternative mechanisms to drive oncogenesis in different systems and that model system selection is important (29). To our knowledge, a systematic evaluation of the FLI portion of EWS/FLI in Ewing sarcoma cells has yet to be reported and so the roles of various regions of $\mathrm{FLI}$ in EWS/FLI-mediated oncogenic transformation remain unknown.

To address this important gap in knowledge, we now report an analysis of the FLI portion of EWS/FLI in Ewing sarcoma cells using our well-validated "knock-down/rescue" system. This model allowed us to identify an uncharacterized region just outside of the DNA-binding domain of FLI that is absolutely essential for EWS/FLI-mediated transcriptional regulation and oncogenic transformation. Furthermore, this system allowed us to explore the mechanistic contributions of this region using luciferase reporter and whole genome RNA-sequencing assays, DNA-binding assays and genomic localization studies, and evaluation of open chromatin regions using ATACsequencing. These studies demonstrate a unique contribution of this region in mediating gene 
expression and subsequent oncogenic transformation that is independent of DNA-binding or the modulation of open chromatin states.

\section{Methods}

\section{Constructs and retroviruses}

Puromycin-resistant retroviral vectors encoding shRNAs targeting Luciferase (iLuc) or the 3'-UTR of endogenous EWS/FLI mRNA (iEF) were previously described $(28,32$ ). Full-length EWS/FLI and mutants (all containing amino-terminal 3xFLAG-tags) were cloned into pMSCV-Hygro (Invitrogen) with sequence details provided in Additional file 1. Luciferase reporter constructs (in pGL3 vectors; Promega Corporation) were previously described (28). The FLI DBD or FLI DBD+ proteins (each containing a carboxyl-terminal 6xHistidine tag) were expressed using pET28a plasmids (EMD Chemicals).

\section{Cell culture methods}

HEK-293EBNA (Invitrogen) and A673 cells (ATCC) were grown, retroviruses produced and used for infection, and soft agar assays were performed as described $(28,32,33)$. STR profiling and mycoplasma testing are performed annually on all cell lines. Dual luciferase reporter assays were performed in HEK-293EBNA cells as previously described (28).

\section{Immunodetection}

Whole-cell or nuclear protein extraction, protein quantification, and Western blot analysis was performed as previously described $(28,32,33)$. Immunoblotting was performed using anti-FLAG M2 mouse (Sigma F1804-200UG), anti- $\alpha-T u b u l i n$ (Abcam ab7291), and anti-Lamin B1 (Abcam ab133741). Membranes were imaged using the LiCor Odyssey CLx Infrared Imaging System. 


\section{qRT-PCR}

Total RNA was extracted from cells using the RNeasy Extraction Kit (Qiagen 74136). Reverse transcription and qPCR were performed using the iTaq Universal SYBR Green 1-Step Reaction Mix (BioRad 1725151) on a Bio-Rad CFX Connect Real-Time System. Primer sequences are found in Additional file 2.

\section{Recombinant protein purification}

Recombinant 6xHistidine-tagged FLI DBD and FLI DBD+ protein was purified as previously described (28).

\section{Fluorescence anisotropy}

Fluorescence anisotropy was performed using recombinant protein and fluorescein-labeled DNA duplexes as previously described using sequences provided in Additional file 3 (28).

\section{CUT\&RUN and Analysis}

Two biological replicates for each knock-down/rescue sample were analyzed by CUT\&RUN using the anti-FLAG M2 mouse antibody (Sigma F1804-200UG) as described and sequenced with the Illumina HiSeq4000 (32). Raw reads were trimmed, de-duplicated, aligned to hg19 reference genomes, and peaks were called using macs2 and DiffBind (Bioconductor) using l"EF + Empty Vector" samples as controls (34). Bigwig files combining two replicates with normalization option "RPGC" were created using Deeptools (35). Overlapping peak analysis was completed using R packages ChIPpeakAnno and Genomic Ranges (36, 37).

\section{RNA-sequencing and Analysis}

RNA-sequencing was performed on two biological replicates each for knock-down/rescue A673 sample. TruSeq Stranded mRNA Kit (Illumina Cat. No. 20020594) was used to prepare cDNA 
libraries from total RNA and sequenced on Illumina HiSeq4000 to generate 150-bp paired-end reads. Reads were analyzed for quality control, trimmed, aligned to the human genome and analyzed for differential analysis (using FASTQC, Multiqc, Trim_galore, STAR version 2.5.2b, DESeq2) (38). GSEA (Version 4.0.3) analysis was performed on RNA-sequencing data (39). Significantly activated and repressed genes were defined using a log2(FC) of $|1.5|$ cutoff for EF and $\mathrm{EF} \mathrm{DBD}+$ to create gene sets. EF DBD genes were used as the rank-ordered gene list to compare with these gene sets. RNA-expression scatterplot analysis was performed as previously

187 described (32).

\section{ATAC-sequencing and Analysis}

190

ATAC-sequencing was performed on two separate biological replicates for knock-down/rescue A673 cells as previously described and sequenced with Illumina HiSeq4000 (40, 41). The ENCODE pipeline was used for trimming, alignment to hg19 reference genome, and peak calling on individual replicates (ENCODE Project). RegioneR was used to perform permutation test and test significance of overlapping ATAC peaks in different samples (37). EnrichedHeatmap, ggplot2, ChIPpeakAnno, and GenomicRanges were used to calculate overlapping regions and create heatmaps $(36,37,42,43)$. Differential ATAC peak analysis was completed using DiffBind (Bioconductor) and DESeq2 with an FDR<0.05 (38).

\section{Statistical Analysis}

Luciferase assay, soft agar assay, and PCR data are presented as mean \pm SEM. Fluorescence anisotropy data are presented as mean \pm standard deviation. Significance of experimental results was determined using a Student's t-test for comparison between groups. P-values less than 0.05 were considered to be significant.

\section{Results}




\section{Amino- and carboxyl-terminal regions of FLI are dispensable for EWS/FLI-mediated}

\section{transcriptional activation in luciferase reporter assays}

We first sought to determine the role of the amino- and carboxyl-regions of FLI in EWS/FLImediated transcriptional activation using a well-defined luciferase reporter assay containing a 20xGGAA-microsatellite response element and a minimal promoter (28). We used the "type IV" EWS/FLI fusion (containing regions encoded by exons 1-7 of EWSR1 fused to exons 7-9 of FLI1)

213 as the full-length protein (containing the 3xFLAG-tag), as this has been extensively used in our 214 previous studies $(28,32)$. We created 3xFLAG-tagged constructs to express "EF $\Delta N-F L I$ " and "EF $\Delta \mathrm{C}$-FLI" mutants that harbor deletions in the FLI portion of the fusion that were either aminoterminal to or carboxyl-terminal to the FLI DNA-binding domain, respectively (Figure 1A). EF $\Delta$ Cmodel system (31). Expression plasmids encoding these proteins were co-transfected with the 20xGGAA-microsatellite luciferase reporter into HEK-293EBNA cells. All three proteins were demonstrate that neither the amino-terminal nor the carboxyl-terminal region of FLI is required for transcriptional activation mediated by EWS/FLI in this system.

Regions immediately adjacent to the DNA-binding domain of FLI are required for oncogenic function of EWS/FLI in a Ewing sarcoma cellular model

227 We next hypothesized that the only critical region in the FLI portion of EWS/FLI is the ETS DNA228 binding domain itself. The ETS DNA-binding domain of FLI is not well-defined in the published 229 literature. The ETS domain is often referred to as an 85-amino acid sequence $(18,19,21)$. 
231 domain that included short amino- and carboxyl-extensions to the 85-amino acid "core" $(7,44)$.

232 To test both possible "ETS domains", we created two new mutant forms of EWS/FLI: "EF DBD"

233 that fuses EWS directly to the 85-amino acid ETS domain and "EF DBD+" that fused EWS to a

234 102-amino acid ETS DNA-binding domain (containing 7- and 10-amino acid extensions on the

235 amino-terminal and carboxyl-terminal sides of DBD, respectively) that our laboratory has used in

236 prior studies (Figure 2A) (26).

238 Similar levels of protein expression were observed following transfection into HEK-293EBNA cells

239 (Supplemental Figure 1A). Luciferase reporter assays using the 20xGGAA-microsatellite 240 response element revealed that both $E F$ DBD and EF DBD+ induced robust transcriptional 241 activation and were even more active than full-length EWS/FLI itself (EF) (Figure 2B, $p$ 242 value $<0.001)$

244 To determine whether the results observed using the luciferase reporter assay would translate to a more relevant Ewing sarcoma cellular model, we used our "knock-down/rescue" system to replace endogenous EWS/FLI with exogenous constructs in patient-derived A673 Ewing sarcoma

247 cells (45). Briefly, retrovirally-expressed shRNAs targeting a control gene (iLuc) or the 3'-UTR of endogenous EWS/FLI (iEF) were introduced and efficient reduction of endogenous EWS/FLI mRNA was achieved (Figure 2C). Exogenous expression of EWS/FLI was "rescued" through retroviral expression of cDNA constructs (EF, EF DBD, and EF DBD+) lacking the endogenous 251 3'-UTR (Figure 2D).

253 These "knock-down/rescue" cells were seeded into soft agar to measure anchorage-independent 254 colony formation as a measure of oncogenic transformation (Figure 2E-F). Positive control cells 255 (iLuc + Empty Vector) showed high rates of colony formation, while cells with diminished levels 256 of EWS/FLI (iEF + Empty Vector) showed a near total loss of transformation capacity that was 
257

258

259

260

261

262

263

264

265

266

267

268

269

270

271

272

273

274

275

276

277

278

279

280

281

282

rescued by re-expression of full-length EWS/FLI (iEF + EF). (Figure 2E-F). Interestingly, expression of $\mathrm{EF} \mathrm{DBD}+(\mathrm{iEF}+\mathrm{EF} \mathrm{DBD}+)$ rescued colony formation to the same level as fulllength exogenous $\mathrm{EF}$, but the smaller EF DBD construct completely failed to rescue colony formation (Figure 2E-F, p-value $<0.005$ ). These data define a significant functional difference between EF DBD and EF DBD+ in the A673 Ewing sarcoma model that is not correlated to their transcriptional activity in the luciferase reporter assay.

\section{DNA-binding and genomic localization of EWS/FLI are nearly identical in FLI domain} mutants

The inability of EF DBD to rescue A673 cell colony growth suggested a loss of a critical function as compared to EF DBD+. The only difference between the EF DBD and EF DBD+ constructs is in the 17-amino acids flanking the 85-amino acid DNA-binding domain core. We therefore reasoned that these flanking amino acids may contribute to EWS/FLI DNA-binding affinity. To test this hypothesis, we performed in vitro fluorescence anisotropy studies to compare the ability of FLI DBD or FLI DBD+ recombinant protein to bind fluorescein-labeled DNA duplexes (Figure 3A, Supplemental Figure 2A-B). We tested an ETS high affinity (HA) site, a 2xGGAA-repeat microsatellite, and a 20xGGAA-repeat microsatellite (Figure 3B-D). We found that both FLI DBD and FLI DBD+ bound each DNA element with similar dissociation constant $\left(K_{D}\right)$ values (Figure 3B-D). These data discount the idea that a significant difference in DNA-binding affinity is the underlying defect in EF DBD.

Although in vitro DNA-binding was nearly identical between FLI DBD and FLI DBD+ recombinant proteins, we next considered if differences in DNA-binding may only be revealed in the context of a chromatinized human genome. To assess this possibility, we performed CUT\&RUN (Cleavage Under Targets \& Release Under Nuclease) to determine the genomic localization patterns of our 3xFLAG-tagged EF, EF DBD, and EF DBD+ proteins in A673 cells using our knock-down/rescue 
283

284

285

286

287

288

289

290

291

292

293

294

295

296

297

298

299

300

301

302

303

304

305

306

307

system $(32,46)$. An anti-FLAG antibody was used to ensure that we evaluated the localization of the exogenous "rescue" constructs and not any low-level residual EWS/FLI remaining after the knock-down. We found that CUT\&RUN identified a similar number of binding peaks between fulllength EF (14,040), EF DBD+ (14,970), and EF DBD $(14,394)$. Comparison of the binding locations for each construct demonstrated that $90 \%$ of EF DBD peaks overlap with those of EF and EF DBD+ (Figure 3E, adjusted p-value < 0.001). Further exploration of EWS/FLI-bound highaffinity sites and microsatellites did not identify any significant differences between EF DBD and EF or EF DBD+ (representative peak tracks are shown in Figure 3F-H). Taken together, these data indicate that there are no large-scale changes in DNA-binding capabilities that might explain the inability of EF DBD to rescue oncogenic transformation in Ewing sarcoma cells.

\section{EF DBD exhibits a hypomorphic gene regulatory capability in Ewing sarcoma cells}

The above studies demonstrated that genome-wide localization is nearly-identical between the full-length and mutant EWS/FLI constructs. Although luciferase assays (Figure 2B) showed strong transcriptional activation by EF DBD, we next considered the possibility that transcriptional regulatory function of EF DBD might be disrupted in a more relevant Ewing sarcoma model. To test this hypothesis, we performed RNA-sequencing on knock-down/rescue cells expressing fulllength EWS/FLI (EF), EF DBD+, or EF DBD.

Full-length EWS/FLI (EF) regulated 4,124 genes and EF DBD+ regulated 3,374 genes (at adjusted $p$-values $<0.05)$. Importantly, $90 \%$ of the genes regulated by EF DBD+ were also regulated by EF. In contrast, EF DBD regulated only 964 genes (adjusted p-value $<0.05$ ). To determine if activated or repressed genes were disproportionately affected, we analyzed each group separately. There was a similar loss of regulation in each group, although the genes that were regulated by EF DBD mostly overlapped with the fully-functional constructs (Figure 4A-B). 
We next performed a more detailed evaluation of the RNA-sequencing data using Gene Set Enrichment Analysis (GSEA). We asked where the activated and repressed gene sets of EF DBD fall in comparison to the rank-ordered gene expression list of EF DBD+. We found very strong correlations of both the activated and repressed gene sets (|NES| of 3.5 and 2.65, respectively, $p$ $<0.001$; Figure 4C-D). Even stronger correlations were observed when EF DBD-regulated gene sets were compared with EF activated and repressed genes (|NES| of 7.09 and 5.65, respectively, $p<0.001$; Supplemental Figure 3A-B).

Closer inspection of the GSEA results revealed a near-complete "stacking" of the EF DBDregulated genes at the furthest edges of the EF DBD+ (or full-length EF) rank-ordered lists. This suggested that EF DBD may only be able to significantly rescue a portion of the EF DBD+ or EFregulated genes, while other genes are still regulated, though to a lesser extent and are not called as significant. We therefore hypothesized that EF DBD functions as an attenuated, hypomorphic version of EWS/FLI. To test this hypothesis, we performed a scatterplot analysis to compare the ability of these constructs to rescue previously-reported EWS/FLI-regulated genes (47). On the $x$-axis, we plotted the expression levels of genes regulated by the full-length EF construct (activated genes in Figure 4E and repressed genes in Supplemental Figure 3C). On the y-axis, we plotted the expression levels of genes regulated by EF DBD+ or EF DBD. Transcriptional regulation by EF DBD+ at activated and repressed genes was highly correlated with regulation by $E F$ (slope $=0.88$ with $R=0.93$ and slope $=0.94$ with $R=0.97$, respectively; $p$-value $<2.2 e-16$; Figure 4E left panel, Supplemental Figure 3C left panel). In contrast, EF DBD demonstrated much weaker correlations (slope $=0.32$ with $\mathrm{R}=0.54$ for activated genes, $\mathrm{p}$-value $<2.5 \mathrm{e}-13$; slope $=0.54$ with $\mathrm{R}=0.78$ for repressed genes, $\mathrm{p}$-value $<2.2 \mathrm{e}-16$; Figure $4 \mathrm{E}$ right panel, Supplemental Figure $3 \mathrm{C}$ right panel). As regulation of EF DBD was still correlated with $\mathrm{EF}$, these data suggested that it is regulating a similar set of genes, albeit more weakly than EF or EF DBD+. 
Taken together, these data indicate that EF DBD is significantly attenuated in its ability to both up- and down-regulate gene expression in patient-derived Ewing sarcoma cells. Thus, EF DBD is best considered a transcriptional regulatory hypomorph, even though its DNA-binding function is intact. The loss of oncogenic potential of EF DBD appears to be due to an underlying defect in transcriptional regulatory capability. This is an unanticipated result as the transcriptional regulation function of EWS/FLI was considered to be mediated solely by the EWS-portion of the fusion with the FLI-portion contributing only DNA-binding function.

\section{Capacity of EWS/FLI to mediate chromatin state is unaltered by deletions surrounding the}

\section{FLI DNA-binding domain}

345 It was recently reported that EWS/FLI functions as a pioneer transcription factor to open regions of chromatin that were previously closed $(9,15)$. As chromatin accessibility is a general necessity for transcriptional regulation, we next evaluated the role of EWS/FLI and its mutants on creation (or maintenance) of open chromatin states by performing ATAC-sequencing in our knockdown/rescue system. To focus on the role of the EWS/FLI mutants on chromatin accessibility, we ATAC signal (Figure 5A), indicating that most EWS/FLI binding peaks are associated with open chromatin states.

To determine if EF DBD is defective in opening chromatin, we compared the ATAC signal at 356 regions bound by EF DBD and those bound by EF DBD+. We found that almost 95\% of ATAC 357 peaks were shared between EF DBD+ and EF DBD (Figure 5B), suggesting that there were not 358 significant differences in accessible chromatin associated with the two mutants. 
360

361

362

363

364

365

366

367

368

369

370

371

372

373

374 Finally, we sought to determine which flanking region of EF DBD+ (that is missing in EF DBD) is

375

376

377

To determine if more subtle differences in open chromatin might be associated with the capability of each mutant to regulate gene expression, we performed a heatmap analysis (Supplemental Figure 4A-B). At EWS/FLI-bound loci near genes that were regulated by EF DBD+ (but not EF DBD), we were surprised to find that the level of ATAC signal was similar in cells expressing EF DBD+ as compared to those expressing EF DBD. Interestingly, we also noted that the ATAC signal was similar at these sites in EWS/FLI knock-down cells (EF KD), indicating that the loss of EWS/FLI is not associated with a closing of the open chromatin state, at least in this system. Tracks comparing RNA-sequencing, CUT\&RUN, and ATAC signal at representative genes only are shown in Figure 5C-D. These data indicate that the dysfunction of EF DBD in mediating gene regulation is not a consequence of an altered pioneer-type function to induce or maintain an open chromatin state at regulated genes.

\section{A fourth alpha-helix of the FLI ETS DNA-binding domain is essential for EWS/FLI-mediated} oncogenic transformation

critical for oncogenic transformation. We engineered EF DBD+ constructs harboring deletions of either the amino-terminal 7-amino acids or the carboxyl-terminal 10-amino acids surrounding the core 85-amino acid DNA-binding domain of FLI (EF DBD+ $\Delta \mathrm{N}$ or EF DBD+ $\Delta \mathrm{C}$, respectively; Figure 6A). Similar expression of each protein construct was observed in A673 cells utilizing our knock-down/rescue system (Figure 6B). Soft agar colony-forming assays demonstrated that EF $\mathrm{DBD}+\Delta \mathrm{N}$ was fully-functional while $\mathrm{EF} \mathrm{DBD}+\Delta \mathrm{C}$ completely lost the ability to transform $\mathrm{A} 673$ cells (Figure 6C-D). These results clearly demonstrate that the 10-amino acids downstream of the FLI DNA-binding domain are essential for EWS/FLI-mediated oncogenesis. 
Analysis of a previously published FLI protein crystal structure revealed that this 10 -amino acid sequence forms two additional beta-turns and a fourth alpha-helix downstream of the winged helix-turn-helix DNA-binding domain of FLI (44). Interestingly, this same study demonstrated that recombinant FLI protein is capable of homodimerization when bound to an ETS HA site via interactions between this fourth alpha-helix of one FLI molecule with the $a_{1}$-helix of another FLI molecule and that homodimerization was lost when a critical phenylalanine was mutated to alanine in this region (F362A) (44). We found that introduction of the F362A mutation to our EF DBD+ construct had no effect on oncogenic transformation in our A673 knock-down/rescue model system, indicating that homodimerization is not required for the oncogenic potential of EWS/FLI (Supplemental Figure 5A-D).

\section{Discussion}

Ewing sarcoma represents a unique opportunity to understand how a single fusion protein mediates oncogenic transformation (8). The EWS/FLI fusion functions as an aberrant transcription factor to dysregulate the expression of several thousand genes and drive oncogenesis, but the mechanistic details of how EWS/FLI modulates this process are only beginning to be understood. It has long been recognized that the EWS-portion functions as a strong transcriptional activation domain (11). In recent years, it has become appreciated that this domain has unique biophysical characteristics that are important for its functions of self-association, recruitment of epigenetic regulators, and interaction with the basal transcriptional machinery that all cooperate to regulate gene expression $(9,14-17)$.

Although several studies suggested that the regions outside of the ETS DNA-binding domain of FLI may be important for EWS/FLI function, the FLI-portion of the fusion has largely been viewed as simply contributing DNA-binding function. In the current study, we took a systematic approach 
409

410

411

412

413

414

415

416

417

418

419

420

421

422

423

424

425

426

427

428

429

430

431

432

433

434

to understand the contributions of FLI to EWS/FLI activity in the context of a Ewing sarcoma cellular background. This allowed us to define a previously unappreciated role for the fourth alphahelix of the extended FLI DNA-binding domain in transcriptional regulation. This alpha-helix does not appear to be important for the DNA-binding, genomic localization, or chromatin accessibility functions of EWS/FLI. Instead, loss of this helix results in a significant loss of gene-regulatory function that culminates in a complete loss of oncogenic transformation mediated by EWS/FLI.

The exact mechanism by which the fourth alpha-helix participates in gene regulation will require additional studies. One possibility is that the fourth alpha-helix is involved in protein-protein interactions with adjacent transcription factors. For example, it has been reported that EWS/FLI interacts with Serum Response Factor (SRF) on serum response elements to form a ternary complex with DNA that is required to regulate transcription (48). It was also shown that the AP-1 members, Fos-Jun, bind to AP-1 sites adjacent to ETS high-affinity sites and form a ternary complex with EWS/FLI (49). Although each of these interactions specifically occur with the FLI portion of EWS/FLI, they each occur outside of the regions of FLI contained in our EF DBD or EF DBD+ mutants and as such, do not readily explain the differences in activity observed between the proteins (49). EWS/FLI may interact with other transcription factors as well. However, we do not favor a loss of such EWS/FLI-transcription factor interactions as the most likely cause of the massive loss of transcriptional function by EF DBD. We reason that if there were losses of EWS/FLI interactions with specific transcription factors, we would have expected a more limited loss of gene expression (rather than the $\sim 70 \%$ loss we observed for EF DBD). Furthermore, the formation of ternary complexes between pairs of transcription factors with DNA tend to stabilize DNA binding. As such, we might also have anticipated a significant change in genomic localization of EF DBD, which was not observed. We currently favor a model whereby the fourth alpha-helix interacts with epigenetic regulators, and/or components of the core transcriptional machinery, that are required for global gene regulation, rather than regulation limited to specific loci. 
436 Work in NIH3T3 mouse fibroblasts suggested a role for the carboxyl-terminal region of FLI in

437 mediating transcriptional down-regulation by EWS/FLI (31). Our work here rules out a significant

438 role for this region in EWS/FLI-mediated oncogenesis. Additionally, luciferase reporter assays

439 have long been used as functional screens, but our results show that activation on a luciferase

440 reporter in an artificial system does not necessarily translate to a Ewing sarcoma model. Indeed,

441 we also note that we did not see direct evidence of the pioneer-type function of EWS/FLI in the

442 Ewing sarcoma model, which had primarily been observed in a mesenchymal stem cell model

443 (9). In our system, EWS/FLI-occupied sites remained open and accessible following knock-down

of EWS/FLI. It may be that the $80-90 \%$ knock-down we achieved was insufficient to allow for chromatin closing of those loci, or perhaps insufficient time was provided to allow for chromatin closing. Nevertheless, changes in chromatin accessibility were not associated with the

447 transcriptional dysfunction exhibited by EF DBD. These findings highlight the importance of analyzing EWS/FLI activity in a relevant Ewing sarcoma cellular context.

It is important to note that a detailed comparison of protein structures of ETS family members

451 revealed that many of these proteins harbor this additional fourth alpha-helix just downstream of

452 their DNA-binding domains. Therefore, the work presented here may have relevance beyond the 453 EWS/FLI-associated Ewing sarcoma context. For example, Ewing sarcoma translocations involve 454 one of five closely-homologous ETS family members (FLI, ERG, FEV, ETV1, and ETV4) (11). 455 Additionally, TMPRSS2-ERG fusions exist in approximately 50\% of prostate cancer cases, with 456 TMPRSS2-FEV, -ETV1, -ETV4, and -ETV5 fusions found in other patients (50). In fact, many ETS 457 family members have been implicated in the oncogenesis of numerous solid and liquid tumor 458 types via mechanisms of over-expression, amplification, mutations, and translocations (20). As 459 the functional motif we identified as crucial for EWS/FLI activity is conserved in numerous other 
ETS factors, the data presented in this report may have wide-ranging implications for oncogenesis

461 in multiple tumor types.

\section{Conclusions}

464 In summary, we have taken a systematic structure-function approach to identify a previously unappreciated region in the extended FLI DNA-binding domain that is required for transcriptional regulation and oncogenic transformation mediated by EWS/FLI. This transcriptional function is

467 distinct from the DNA-binding and genomic localization functions typically associated with the

468 ETS domain. This work has implications not only for the development of Ewing sarcoma, but may 469 also be useful in understanding the development of other ETS-associated tumors and, perhaps, 470 even normal ETS transcriptional function. A better understanding of this newly-defined region may 471 lead to novel approaches for therapeutically-targeting EWS/FLI, as well as other ETS factors. 472 Ultimately, these efforts may lead to more efficacious therapeutic options for patients with this 473 devastating disease.

475 Abbreviations

476 ATAC-sequencing: Assay for Transposase-Accessible Chromatin using sequencing; CUT\&RUN:

477 Cleave Under Targets \& Release Under Nuclease; cDNA: complementary DNA; DBD: DNA478 binding domain; DNA: deoxyribonucleic acid; EF: experimental EWS/FLI cDNA constructs; ERG: 479 ETS-related gene; ETS: E26 transformation specific; ETV1: ETS variant transcription factor 1; 480 ETV4: ETS variant transcription factor 4; ETV5: ETS variant transcription factor 5; EWSR1 (EWS): 481 Ewing sarcoma breakpoint region 1; FET: FUS/TLS, EWSR1, TAF15; FEV: Fifth Ewing variant 482 protein; FLI1 (FLI): Friend leukemia integration 1; FUS: Fused in sarcoma; GSEA: Gene Set 483 Enrichment Analysis; HA: high-affinity; HEK-293EBNA: Human embryonic kidney-293 cell line 484 expressing Epstein Barr nuclear antigen; IGV: Integrated Genome Viewer; KD: knock-down; K $\mathrm{K}_{D}=$ 
485 dissociation constant; log2(FC): log2(Fold Change); mRNA: messenger RNA; $\mu$ Sat:

486 microsatellite; NES: Normalized Enrichment Score; qRT-PCR: quantitative Reverse

487 Transcriptase- Polymerase Chain Reaction; RNA: ribonucleic acid; SEM: standard error of the

488 mean; SRF: Serum Response Factor; STR: short tandem repeats; TMPRSS2: Transmembrane

489 protease, serine 2

490

491 Declarations

492 Ethics Approval and Consent to Participate

493 Not applicable.

494

495 Consent for publication

496 Not applicable.

497

498 Availability of data and materials

499 The sequencing datasets generated and analyzed during the current study are available in the

500 Gene Expression Omnibus and accessible at [unique identifier number pending]. All other data

501 generated or analyzed during this study are available from the corresponding author on

502 reasonable request.

503

504 Competing interests

505 SLL declares a competing interest as a member of the advisory board for Salarius

506 Pharmaceuticals. SLL is also a listed inventor on United States Patent No. US 7,939,253 B2,

507 "Methods and compositions for the diagnosis and treatment of Ewing's sarcoma," and United

508 States Patent No. US 8,557,532, "Diagnosis and treatment of drug-resistant Ewing's sarcoma."

509 This does not alter our adherence to Molecular Cancer policies on sharing data and materials. 


\section{$511 \quad$ Funding}

512 Research reported in this publication was supported by the National Institute of Health 513 award T32 GM068412 to MAB, and U54 CA231641 to SLL. The content is solely the

514 responsibility of the authors and does not necessarily represent the official views of the 515 National Institutes of Health.

\section{Authors Contributions}

518 MAB and SLL are responsible for conceptualization of the project. Investigation was performed 519 by MAB, JCC, JSA, BDS, and BZS. Methodology was formulated by MAB, JSA, ERT, IS, and 520 BZS. Data analysis was performed by MAB, CT, ERT, IS, and MW. Manuscript preparation was 521 completed by MAB and reviewing and editing was performed by all authors. Funding acquisition 522 was completed by MAB and SLL. Supervision was provided by SLL.

\section{Acknowledgements}

525 We thank Dr. Andrea K. Byrum, Dr. Kirsten N. Johnson, Dr. Kathleen I. Pishas, Dr. Jack Tokarsky, 526 and Ariunaa Bayanjargal for thoughtful discussion concerning the hypothesis and methodology 527 of this manuscript. 


\section{References}

1. Delattre O, Zucman J, Plougastel B, Desmaze C, Melot T, Peter M, et al. Gene fusion with an ETS DNA-binding domain caused by chromosome translocation in human tumours. Nature. 1992;359(6391):162-5.

2. Longhi A, Ferrari S, Tamburini A, Luksch R, Fagioli F, Bacci G, et al. Late effects of chemotherapy and radiotherapy in osteosarcoma and Ewing sarcoma patients: the Italian Sarcoma Group Experience (1983-2006). Cancer. 2012;118(20):5050-9.

3. Zucman J, Melot T, Desmaze C, Ghysdael J, Plougastel B, Peter M, et al. Combinatorial generation of variable fusion proteins in the Ewing family of tumours. EMBO J. 1993;12(12):4481-7.

4. Bailly RA, Bosselut R, Zucman J, Cormier F, Delattre O, Roussel M, et al. DNA-binding and transcriptional activation properties of the EWS-FLI-1 fusion protein resulting from the $t(11 ; 22)$ translocation in Ewing sarcoma. Mol Cell Biol. 1994;14(5):3230-41.

5. Aurias A, Rimbaut C, Buffe D, Dubousset J, Mazabraud A. [Translocation of chromosome 22 in Ewing's sarcoma]. C R Seances Acad Sci III. 1983;296(23):1105-7.

6. Turc-Carel C, Aurias A, Mugneret F, Lizard S, Sidaner I, Volk C, et al. Chromosomes in Ewing's sarcoma. I. An evaluation of 85 cases of remarkable consistency of $\mathrm{t}(11 ; 22)(\mathrm{q} 24 ; \mathrm{q} 12)$. Cancer Genet Cytogenet. 1988;32(2):229-38.

7. May WA, Gishizky ML, Lessnick SL, Lunsford LB, Lewis BC, Delattre O, et al. Ewing sarcoma 11;22 translocation produces a chimeric transcription factor that requires the DNA-binding domain encoded by FLI1 for transformation. Proc Natl Acad Sci U S A. 1993;90(12):5752-6.

8. Crompton BD, Stewart C, Taylor-Weiner A, Alexe G, Kurek KC, Calicchio ML, et al. The genomic landscape of pediatric Ewing sarcoma. Cancer Discov. 2014;4(11):1326-41.

9. Riggi N, Knoechel B, Gillespie SM, Rheinbay E, Boulay G, Suva ML, et al. EWS-FLI1 utilizes divergent chromatin remodeling mechanisms to directly activate or repress enhancer elements in Ewing sarcoma. Cancer Cell. 2014;26(5):668-81.

10. Braun BS, Frieden R, Lessnick SL, May WA, Denny CT. Identification of target genes for the Ewing's sarcoma EWS/FLI fusion protein by representational difference analysis. Mol Cell Biol. 1995;15(8):4623-30.

11. Sankar S, Lessnick SL. Promiscuous partnerships in Ewing's sarcoma. Cancer Genet. $2011 ; 204(7): 351-65$.

12. Lessnick SL, Braun BS, Denny CT, May WA. Multiple domains mediate transformation by the Ewing's sarcoma EWS/FLI-1 fusion gene. Oncogene. 1995;10(3):423-31.

13. Sankar S, Bell R, Stephens B, Zhuo R, Sharma S, Bearss DJ, et al. Mechanism and relevance of EWS/FLI-mediated transcriptional repression in Ewing sarcoma. Oncogene. 2013;32(42):5089-100.

14. Erkizan HV, Uversky VN, Toretsky JA. Oncogenic partnerships: EWS-FLI1 protein interactions initiate key pathways of Ewing's sarcoma. Clin Cancer Res. 2010;16(16):407783.

15. Boulay G, Sandoval GJ, Riggi N, lyer S, Buisson R, Naigles B, et al. Cancer-Specific Retargeting of BAF Complexes by a Prion-like Domain. Cell. 2017;171(1):163-78 e19.

16. Spahn L, Siligan C, Bachmaier R, Schmid JA, Aryee DN, Kovar H. Homotypic and heterotypic interactions of EWS, FLI1 and their oncogenic fusion protein. Oncogene. 2003;22(44):6819-29.

17. Kovar H. Dr. Jekyll and Mr. Hyde: The Two Faces of the FUS/EWS/TAF15 Protein Family. Sarcoma. 2011;2011:837474.

18. Liang H, Olejniczak ET, Mao X, Nettesheim DG, Yu L, Thompson CB, et al. The secondary structure of the ets domain of human Fli-1 resembles that of the helix-turn-helix DNA- 
binding motif of the Escherichia coli catabolite gene activator protein. Proc Natl Acad Sci $U$ S A. 1994;91(24):11655-9.

19. Laudet V, Hanni C, Stehelin D, Duterque-Coquillaud M. Molecular phylogeny of the ETS gene family. Oncogene. 1999;18(6):1351-9.

20. Sizemore GM, Pitarresi JR, Balakrishnan S, Ostrowski MC. The ETS family of oncogenic transcription factors in solid tumours. Nat Rev Cancer. 2017;17(6):337-51.

21. Mao X, Miesfeldt S, Yang H, Leiden JM, Thompson CB. The FLI-1 and chimeric EWS-FLI-1 oncoproteins display similar DNA binding specificities. J Biol Chem. 1994;269(27):1821622.

22. Szymczyna BR, Arrowsmith $\mathrm{CH}$. DNA binding specificity studies of four ETS proteins support an indirect read-out mechanism of protein-DNA recognition. J Biol Chem. 2000;275(37):28363-70.

23. Hollenhorst PC, Mclntosh LP, Graves BJ. Genomic and biochemical insights into the specificity of ETS transcription factors. Annu Rev Biochem. 2011;80:437-71.

24. Currie SL, Lau DKW, Doane JJ, Whitby FG, Okon M, McIntosh LP, et al. Structured and disordered regions cooperatively mediate DNA-binding autoinhibition of ETS factors ETV1, ETV4 and ETV5. Nucleic Acids Res. 2017;45(5):2223-41.

25. Regan MC, Horanyi PS, Pryor EE, Jr., Sarver JL, Cafiso DS, Bushweller JH. Structural and dynamic studies of the transcription factor ERG reveal DNA binding is allosterically autoinhibited. Proc Natl Acad Sci U S A. 2013;110(33):13374-9.

26. Gangwal K, Close D, Enriquez CA, Hill CP, Lessnick SL. Emergent Properties of EWS/FLI Regulation via GGAA Microsatellites in Ewing's Sarcoma. Genes Cancer. 2010;1(2):17787.

27. Gangwal K, Lessnick SL. Microsatellites are EWS/FLI response elements: genomic "junk" is EWS/FLI's treasure. Cell Cycle. 2008;7(20):3127-32.

28. Johnson KM, Mahler NR, Saund RS, Theisen ER, Taslim C, Callender NW, et al. Role for the EWS domain of EWS/FLI in binding GGAA-microsatellites required for Ewing sarcoma anchorage independent growth. Proc Natl Acad Sci U S A. 2017;114(37):9870-5.

29. Braunreiter CL, Hancock JD, Coffin CM, Boucher KM, Lessnick SL. Expression of EWSETS fusions in NIH3T3 cells reveals significant differences to Ewing's sarcoma. Cell Cycle. 2006;5(23):2753-9.

30. Welford SM, Hebert SP, Deneen B, Arvand A, Denny CT. DNA binding domainindependent pathways are involved in EWS/FLI1-mediated oncogenesis. J Biol Chem. $2001 ; 276(45): 41977-84$.

31. Arvand A, Welford SM, Teitell MA, Denny CT. The COOH-terminal domain of FLI-1 is necessary for full tumorigenesis and transcriptional modulation by EWS/FLI-1. Cancer Res. 2001;61(13):5311-7.

32. Theisen ER, Miller KR, Showpnil IA, Taslim C, Pishas KI, Lessnick SL. Transcriptomic analysis functionally maps the intrinsically disordered domain of EWS/FLI and reveals novel transcriptional dependencies for oncogenesis. Genes Cancer. 2019;10(1-2):21-38.

33. Pishas KI, Drenberg CD, Taslim C, Theisen ER, Johnson KM, Saund RS, et al. Therapeutic Targeting of KDM1A/LSD1 in Ewing Sarcoma with SP-2509 Engages the Endoplasmic Reticulum Stress Response. Mol Cancer Ther. 2018;17(9):1902-16.

34. Zhang Y, Liu T, Meyer CA, Eeckhoute J, Johnson DS, Bernstein BE, et al. Model-based analysis of ChIP-Seq (MACS). Genome Biol. 2008;9(9):R137.

35. Ramirez F, Ryan DP, Gruning B, Bhardwaj V, Kilpert F, Richter AS, et al. deepTools2: a next generation web server for deep-sequencing data analysis. Nucleic Acids Res. 2016;44(W1):W160-5.

36. Zhu LJ, Gazin C, Lawson ND, Pages H, Lin SM, Lapointe DS, et al. ChIPpeakAnno: a Bioconductor package to annotate ChIP-seq and ChIP-chip data. BMC Bioinformatics. 2010;11:237. 
37. Lawrence M, Huber W, Pages H, Aboyoun P, Carlson M, Gentleman R, et al. Software for computing and annotating genomic ranges. PLoS Comput Biol. 2013;9(8):e1003118.

38. Love MI, Huber W, Anders S. Moderated estimation of fold change and dispersion for RNAseq data with DESeq2. Genome Biol. 2014;15(12):550.

39. Subramanian A, Tamayo P, Mootha VK, Mukherjee S, Ebert BL, Gillette MA, et al. Gene set enrichment analysis: a knowledge-based approach for interpreting genome-wide expression profiles. Proc Natl Acad Sci U S A. 2005;102(43):15545-50.

40. Hodges HC, Stanton BZ, Cermakova K, Chang CY, Miller EL, Kirkland JG, et al. Dominantnegative SMARCA4 mutants alter the accessibility landscape of tissue-unrestricted enhancers. Nat Struct Mol Biol. 2018;25(1):61-72.

41. Buenrostro JD, Giresi PG, Zaba LC, Chang HY, Greenleaf WJ. Transposition of native chromatin for fast and sensitive epigenomic profiling of open chromatin, DNA-binding proteins and nucleosome position. Nat Methods. 2013;10(12):1213-8.

42. Gu Z, Eils R, Schlesner M, Ishaque N. EnrichedHeatmap: an R/Bioconductor package for comprehensive visualization of genomic signal associations. BMC Genomics. 2018;19(1):234.

43. Maag JLV. gganatogram: An R package for modular visualisation of anatograms and tissues based on ggplot2. F1000Res. 2018;7:1576.

44. Hou C, Tsodikov OV. Structural Basis for Dimerization and DNA Binding of Transcription Factor FLI1. Biochemistry. 2015;54(50):7365-74.

45. Martinez-Ramirez A, Rodriguez-Perales S, Melendez B, Martinez-Delgado B, Urioste M, Cigudosa JC, et al. Characterization of the A673 cell line (Ewing tumor) by molecular cytogenetic techniques. Cancer Genet Cytogenet. 2003;141(2):138-42.

46. Skene PJ, Henikoff S. An efficient targeted nuclease strategy for high-resolution mapping of DNA binding sites. Elife. 2017;6.

47. Sankar S, Theisen ER, Bearss J, Mulvihill T, Hoffman LM, Sorna V, et al. Reversible LSD1 inhibition interferes with global EWS/ETS transcriptional activity and impedes Ewing sarcoma tumor growth. Clin Cancer Res. 2014;20(17):4584-97.

48. Watson DK, Robinson L, Hodge DR, Kola I, Papas TS, Seth A. FLI1 and EWS-FLI1 function as ternary complex factors and ELK1 and SAP1a function as ternary and quaternary complex factors on the Egr1 promoter serum response elements. Oncogene. 1997;14(2):213-21.

49. Kim S, Denny CT, Wisdom R. Cooperative DNA binding with AP-1 proteins is required for transformation by EWS-Ets fusion proteins. Mol Cell Biol. 2006;26(7):2467-78.

50. Tomlins SA, Laxman B, Varambally S, Cao X, Yu J, Helgeson BE, et al. Role of the TMPRSS2-ERG gene fusion in prostate cancer. Neoplasia. 2008;10(2):177-88. 
A

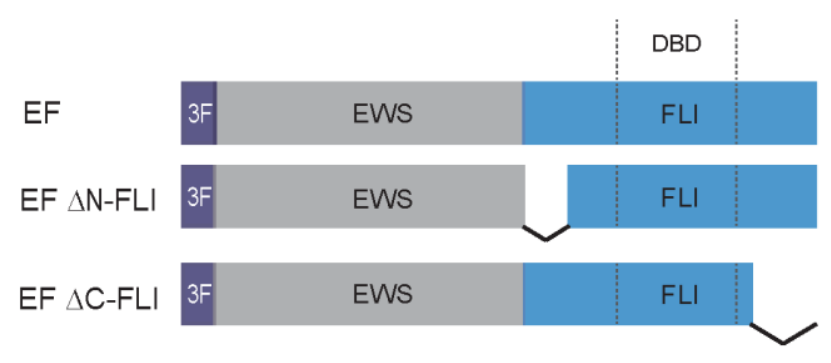

C

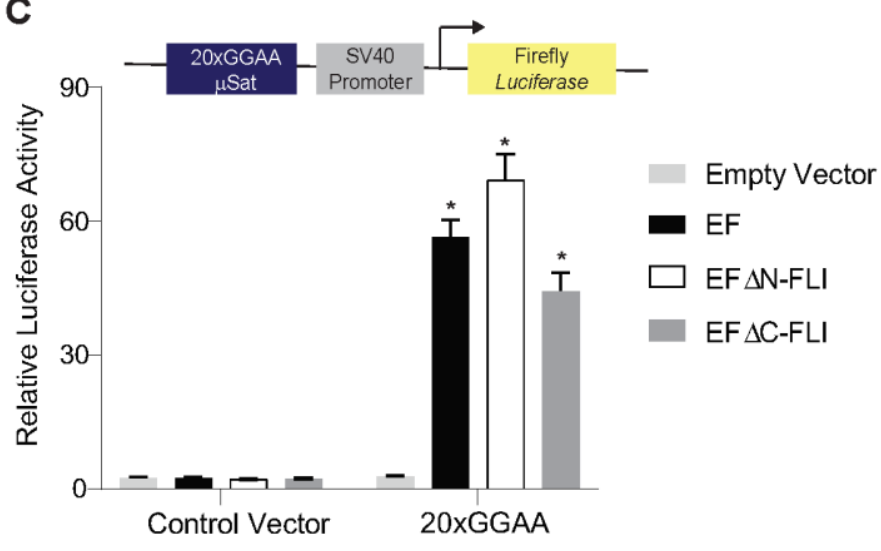

B

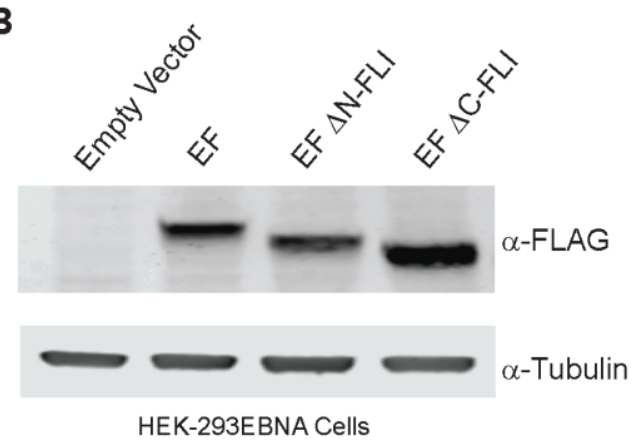

679

680

681

682

683

684

685

686

687

688

689

690

691

692

693

694

695

696

697

698

Figure 1. Amino- and carboxyl-terminal regions of FLI are not required for EWS/FLImediated transcriptional activation.

(A) Protein schematic of 3xFLAG-tagged (3F) EWS/FLI (EF) cDNA constructs with FLI deletions. EWS is represented in grey, FLI is represented in blue, and dashed lines in the FLI portion represent the 85-amino acid ETS DNA-binding domain (DBD) of FLI. In each construct, EWS is fused directly to the FLI portion, but connecting lines are shown here to represent regions of FLI that are eliminated in each construct. EF represents a full-length "type IV" EWS/FLI translocation. EF $\Delta N-F L I$ and EF $\Delta \mathrm{C}-\mathrm{FLI}$ indicate constructs where EWS was fused to a version of FLI with a deletion in the $\mathrm{N}$ - or C-terminal region of, respectively. (B) Western blot of 3xFLAG-tagged EWS/FLI protein expression in HEK-293EBNA cells. Membranes were probed with either $\alpha$-FLAG or $\alpha$-tubulin antibodies. (C) Dual luciferase reporter assay results for the indicated cDNA constructs co-transfected into HEK-293EBNA cells with a Control Vector harboring no GGAArepeats, or a vector containing 20xGGAA-repeats (shown schematically above the graph). Data are presented as mean \pm SEM ( $n=6$ independent replicates). Asterisks indicate that the activity of $\mathrm{EF}, \mathrm{EF} \triangle \mathrm{N}-\mathrm{FLI}$, and $\mathrm{EF} \triangle \mathrm{C}-\mathrm{FLI}$ are each statistically significant when compared to Empty Vector on a 20xGGAA $\mu$ Sat (p-value $<0.05$ ). The activity of EF $\Delta \mathrm{N}-\mathrm{FLI}$ and $E F \Delta \mathrm{C}-\mathrm{FLI}$ are not statistically different from $E F$ on the 20xGGAA $\mu$ Sat ( $p$-value $=0.8$ ). 
A

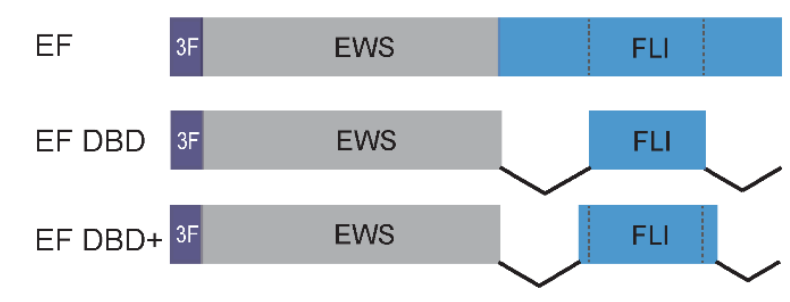

C

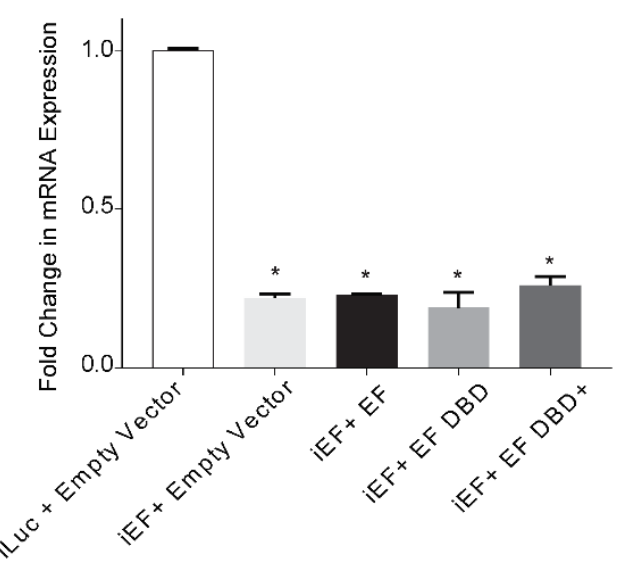

E

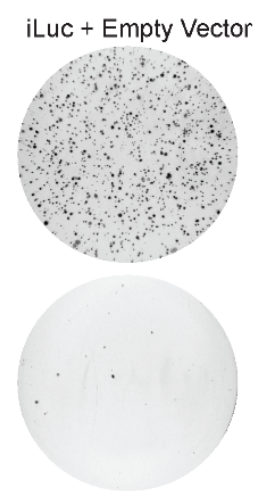

$\mathrm{iEF}+\mathrm{EF} D B D$
B

D
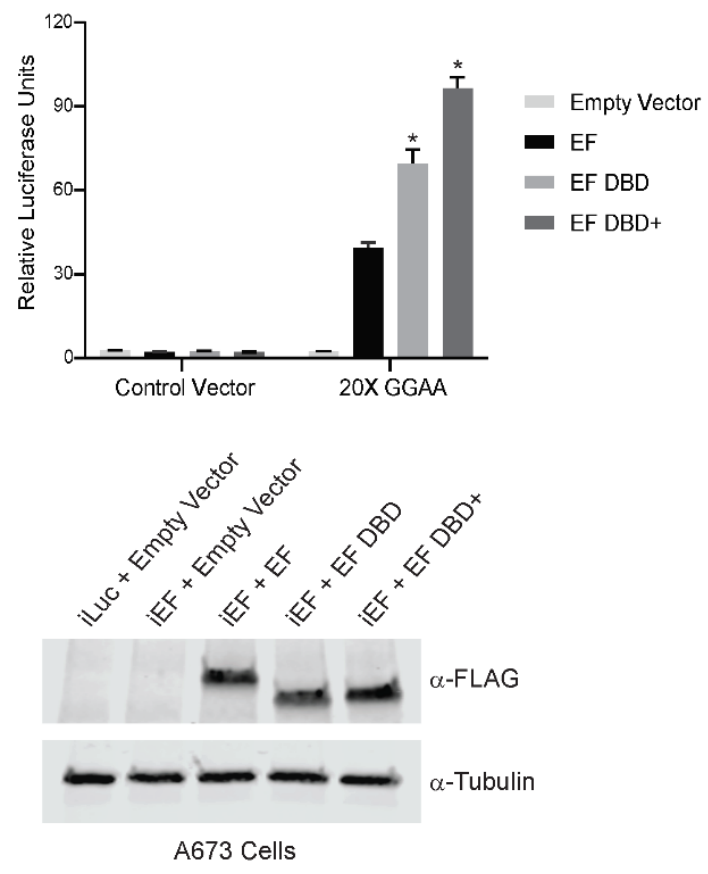

$\mathbf{F}$

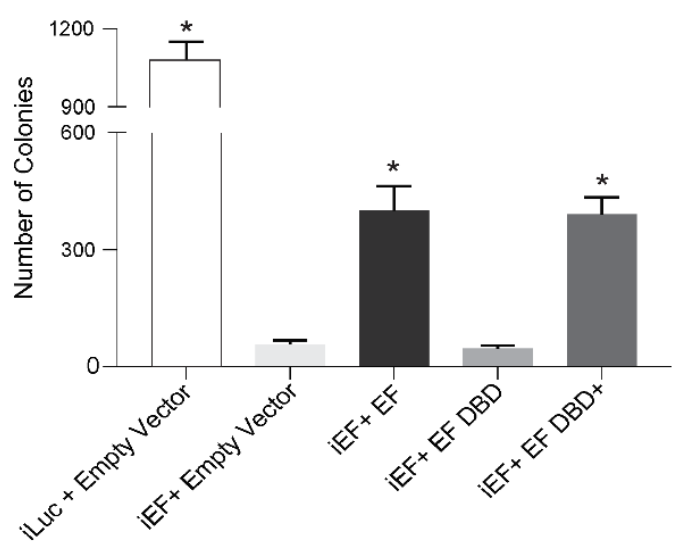

Figure 2. Oncogenic transformation capacity of EWS/FLI affected by short regions surrounding the FLI DBD.

(A) Protein schematic of 3xFLAG-tagged (3F) EWS/FLI cDNA constructs with deleted FLI domain regions. EF represents a full-length type IV EWS/FLI, EF DBD represents EWS fused directly to the 85-amino acid DNA-binding domain of FLI, and EF DBD+ represents EWS fused to a 102 amino acid region of FLI that contains the 85 amino-acid DNA-binding domain with 7 additional amino-acids on the amino-terminal side and 10 additional amino-acids on the carboxyl-terminal side (B) Dual luciferase reporter assay results for the indicated constructs tested on control and 20xGGAA $\mu$ Sat-containing plasmids (as described in Figure 1). Data are presented as mean \pm SEM ( $n=6$ independent replicates). Asterisks indicate that the activity of EF DBD and EF DBD+ are each statistically higher than EF ( $p$-value $<0.001$ ). (C) Representative qRT-PCR results of endogenous EWS/FLI in A673 cells harboring the indicated constructs (iLuc is a control shRNA targeting luciferase and iEF is an shRNA targeting the 3'UTR of endogenous EWS/FLI; $n=1$ ). 
are statistically different as compared to control iLuc + Empty Vector cells ( $p$-value $<0.001)$. (D) Western blot analysis of exogenous EWS/FLI protein expression corresponding to samples shown in panel $\mathrm{C}$. Protein constructs were detected using $\alpha$-FLAG antibody and $\alpha$-Tubulin was used as a loading control. (E) Representative soft agar assay results of A673 Ewing sarcoma cells containing the indicated constructs. (F) Soft agar assay colony formation quantification. Data presented as mean \pm SEM ( $n=9$ independent replicates). Asterisks indicate $p$-value $<0.001$ as compared to iEF + Empty Vector. 
A

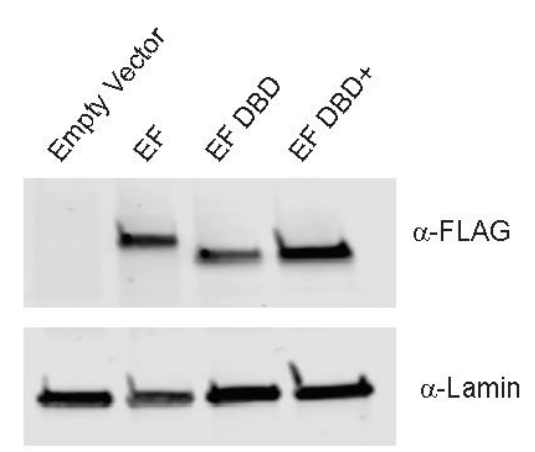

HEK-293EBNA Cells

764

\section{Supplemental Figure 1. EWS/FLI mutant construct expression in HEK-293EBNA cells.} (A) 3xFLAG-tagged full-length EWS/FLI (EF), EF DBD, or EF DBD+ constructs were expressed in HEK-293EBNA cells. Western blot analysis was used to determine expression of these proteins utilizing $\alpha$-FLAG. $\alpha$-Lamin was used as a loading control. 
A

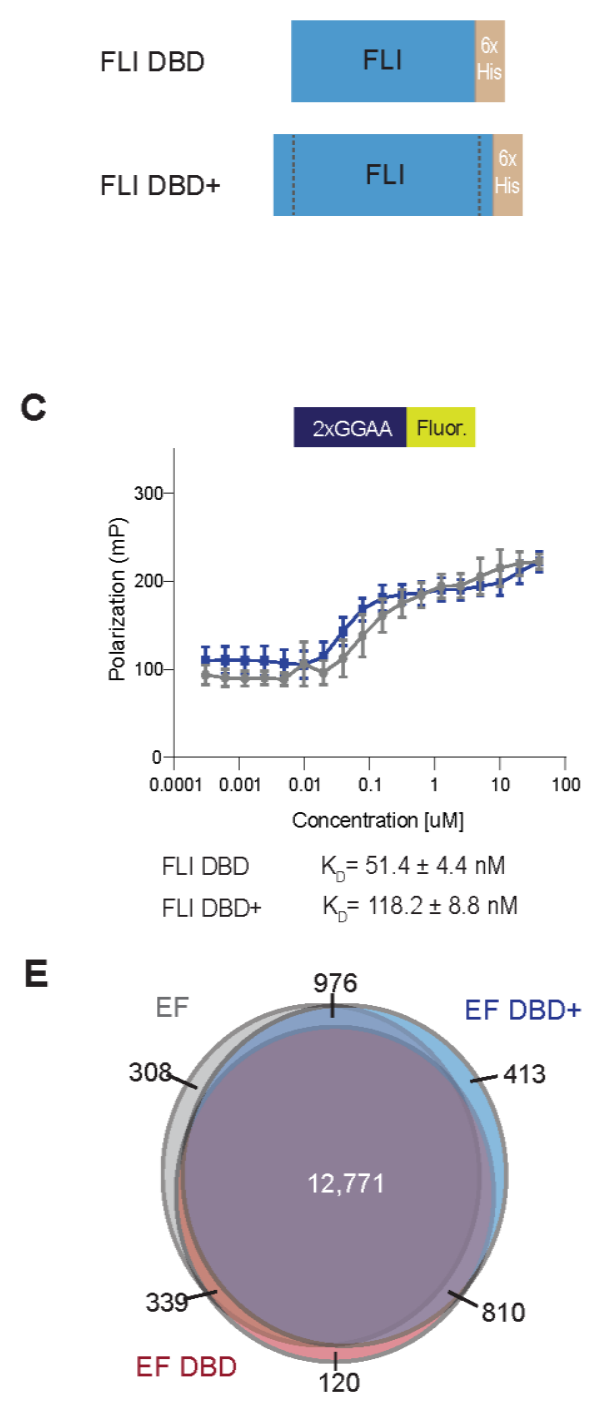

G

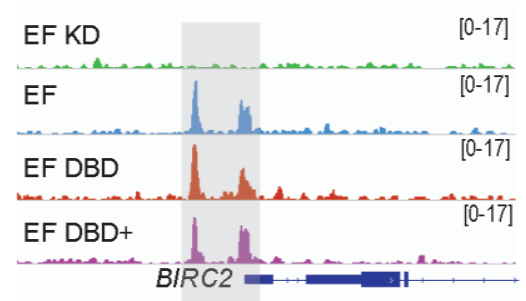

B

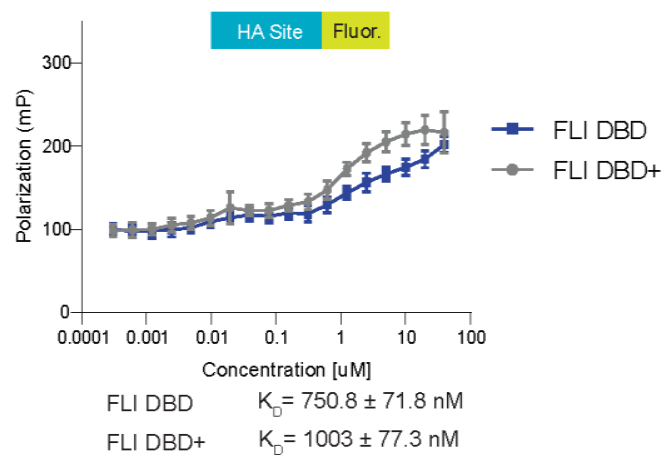

D

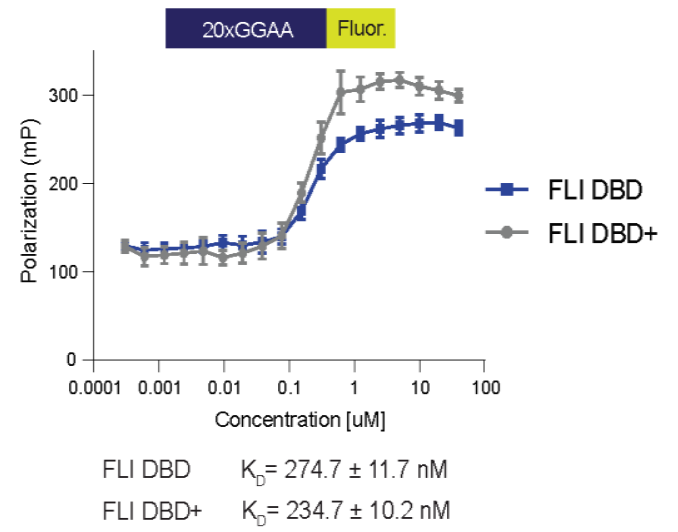

$\mathbf{F}$

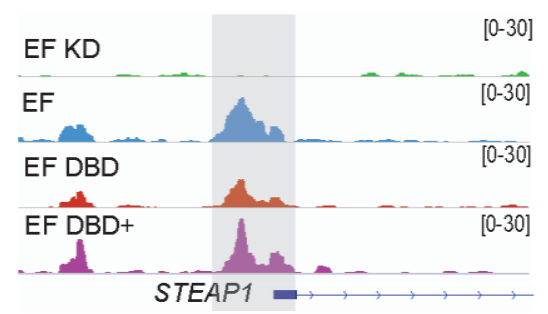

H

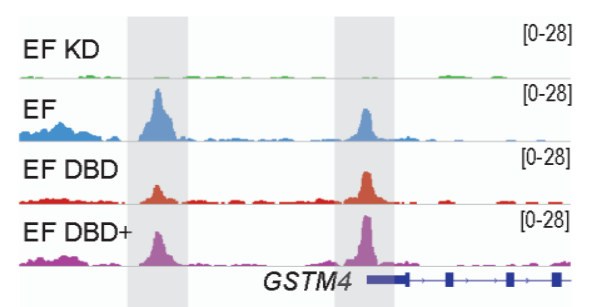

Figure 3. DNA-binding and genomic localization properties of EWS/FLI unaltered by deletions flanking the FLI DNA-binding domain.

(A) Protein schematic of FLI DBD or FLI DBD+ recombinant protein (with C-terminal 6xHistidinetag [6xHis]). (B-D) Fluorescence anisotropy assay results for FLI DBD and FLI DBD+ recombinant proteins $(0-40 \mu \mathrm{M})$ on the following fluorescein-labeled DNA sequences: (B) ETS high affinity (HA) site DNA, (C) 2x-repeat GGAA $\mu$ Sat DNA, and (D) 20x-repeat GGAA $\mu$ Sat DNA ( $n=9$ independent replicates). Dissociation constants $\left(K_{D}\right)$ for FLI DBD and FLI DBD+ are noted for each DNA response element. (E) Venn diagram comparing peaks called in CUT\&RUN for 
$779 \mathrm{EWS} / \mathrm{FLI}$ construct localization in knock-down/rescue cells $(E F=i E F+E F ; E F$ DBD $=\mathrm{iEF}+\mathrm{EF}$ 780 DBD; EF DBD+ = iEF + EF DBD+) when compared to cells that did not contain a rescue construct 781 (iEF + Empty Vector). The number of peaks overlapping between constructs are indicated on the 782 Venn diagram. (F-H) Representative CUT\&RUN peak tracks from IGV are shown for iEF + Empty 783 Vector (EF KD), EF, EF DBD, and EF DBD+ samples. Examples of peaks from EWS/FLI784 associated HA-site regulated genes ([F] STEAP1 and [G] BIRC2) and GGAA- $\mu$ Sat-regulated genes $([\mathrm{H}]$ GSTM4) are highlighted. Peak track scales are shown on the right. 
A

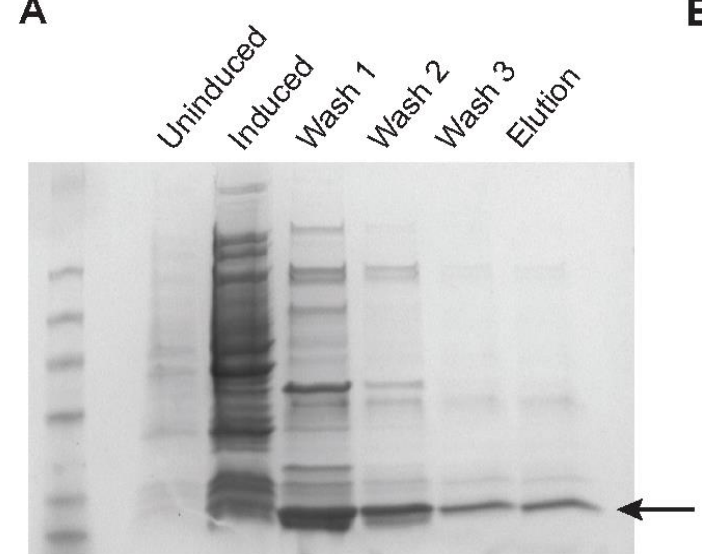

FLI DBD-6xHistidine
B

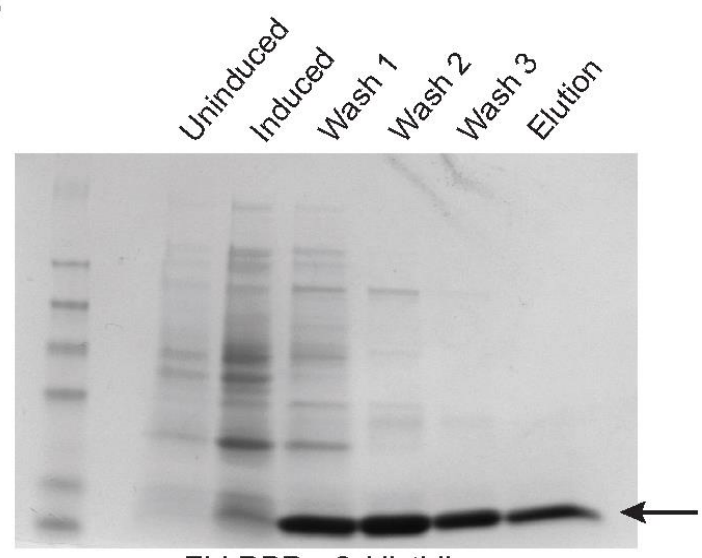

FLI DBD+-6xHistidine

\section{Supplemental Figure 2. Recombinant FLI DBD and FLI DBD+ protein purification.}

(A-B) Samples were taken at several stages of recombinant protein purification for FLI DBD6xHisitidine (A) and FLI DBD+-6xHistidine (B), including: Uninduced bacteria, Induced bacteria, after Wash 1, Wash 2, and Wash 3 following bacterial lysis, and Eluted Fraction. Samples were run on a SDS-PAGE gel and demonstrate good purity at the final elution step. 
bioRxiv preprint doi: https://doi.org/10.1101/2020.10.29.355859; this version posted October 30,2020 . The copyright holder for this preprint (which was not certified by peer review) is the author/funder, who has granted bioRxiv a license to display the preprint in perpetuity. It is made available under aCC-BY-NC 4.0 International license.

A

Genes Activated by EWS/FLI Constructs

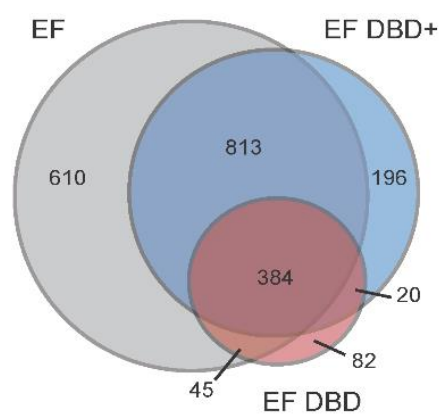

C

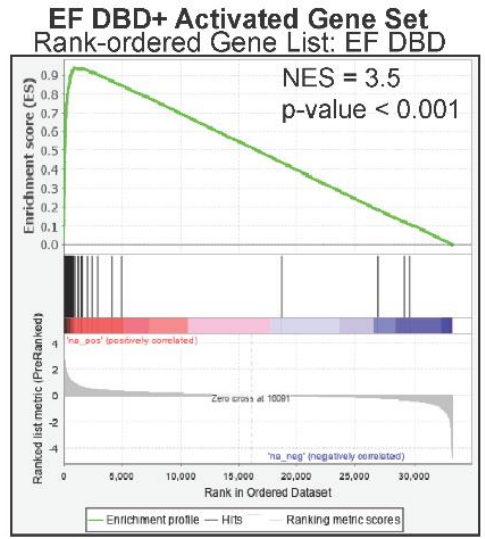

B

Genes Repressed by EWS/FLI Constructs

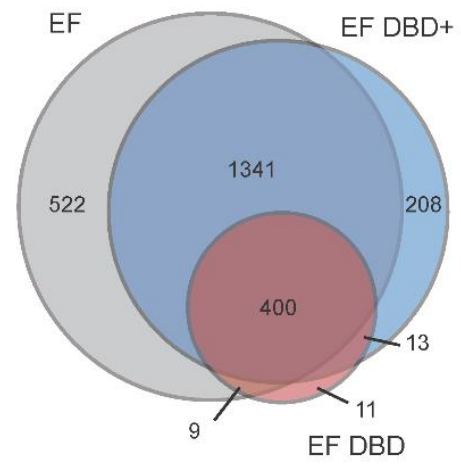

D
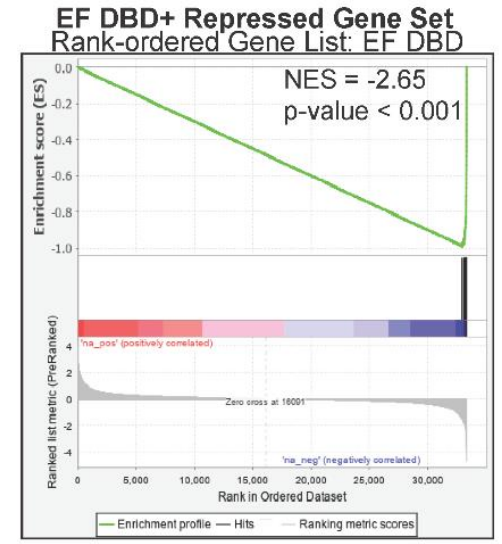

E

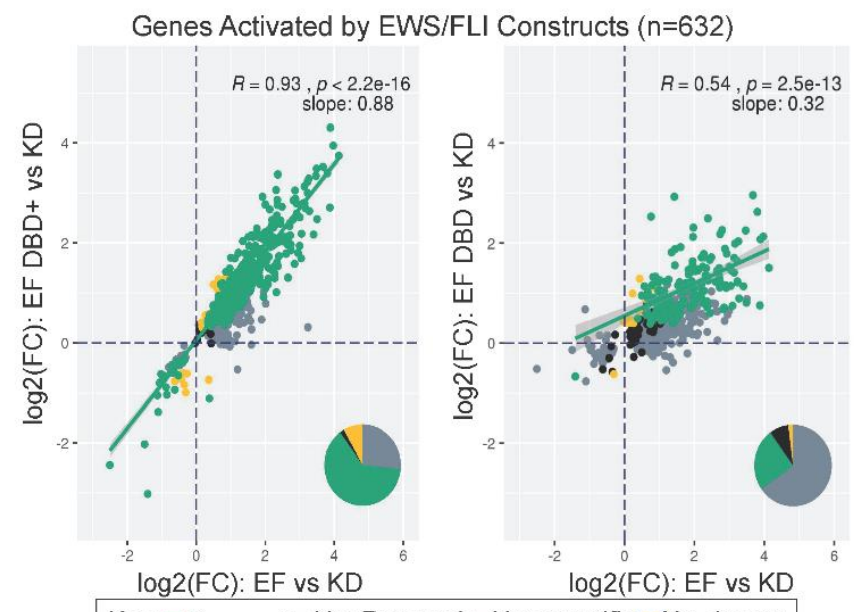

\section{Figure 4. EWS/FLI-driven transcriptional regulation diminished by FLI DBD flanking deletions in Ewing sarcoma cells.}

(A-B) Venn diagram analysis of RNA-sequencing data comparing genes significantly (A) activated or $(B)$ repressed in $A 673$ cells rescued with the indicated constructs (full-length EWS/FLI [EF], EF $\mathrm{DBD}$, and $\mathrm{EF} \mathrm{DBD}+$ ) when compared to A673 cells with no exogenous EWS/FLI construct (iEF + Empty Vector) (adjusted p-value (FDR) < 0.05). (C-D) GSEA analysis comparing all genes regulated by EF DBD as the rank-ordered gene list to $(C)$ genes activated by EF DBD+ $(\log 2(F C)$ $>1.5, F D R<0.05)$ as the gene set or (D) genes repressed by EF DBD+ $(\log 2(F C)<-1.5, F D R<$ 0.05 ) as the gene set. (E) Genes significantly activated by endogenous EWS/FLI were defined 
847 using a previous RNA-sequencing dataset (47). Genes activated by EF, EF DBD, and EF DBD+ 848 were compared to this list of EWS/FLI-activated genes. Scatterplots comparing genes activated 849 by EF (on the x-axis) to EF DBD+ (left) or EF DBD (right) (on the y-axis) were plotted to determine 850 the ability of these constructs to rescue expression these genes. Significance was defined by a $851 \log 2(\mathrm{FC})>0$ and an adjusted $\mathrm{p}$-value $<0.05$. Pearson correlation coefficient and associated $\mathrm{p}$ 852 values with slope are noted on the plots. Pie charts represent the proportion of genes found in 853 each of the described groups is also depicted. 
bioRxiv preprint doi: https://doi.org/10.1101/2020.10.29.355859; this version posted October 30, 2020. The copyright holder for this preprint (which was not certified by peer review) is the author/funder, who has granted bioRxiv a license to display the preprint in perpetuity. It is made available under aCC-BY-NC 4.0 International license.

A

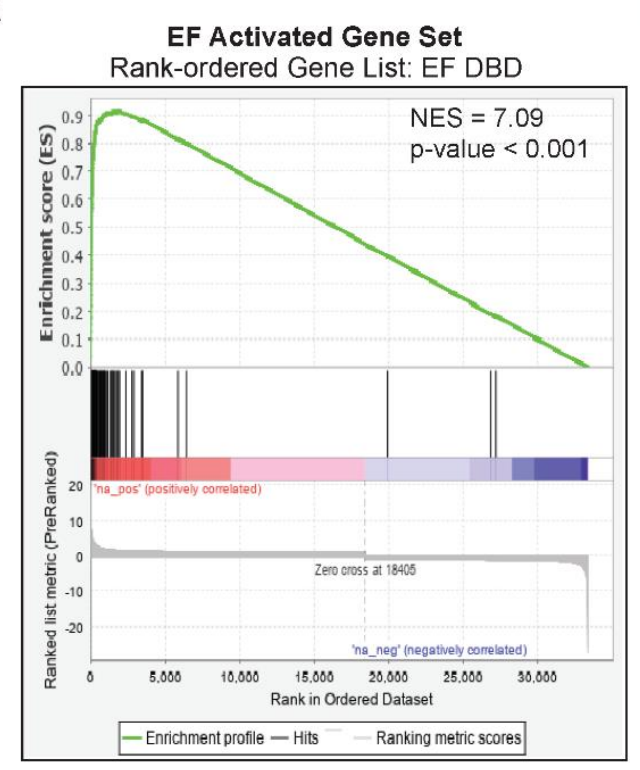

B

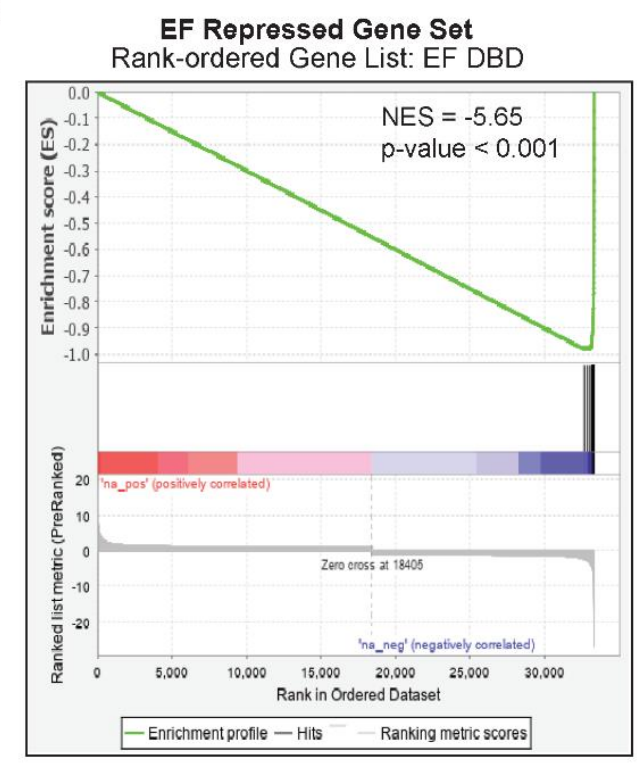

C

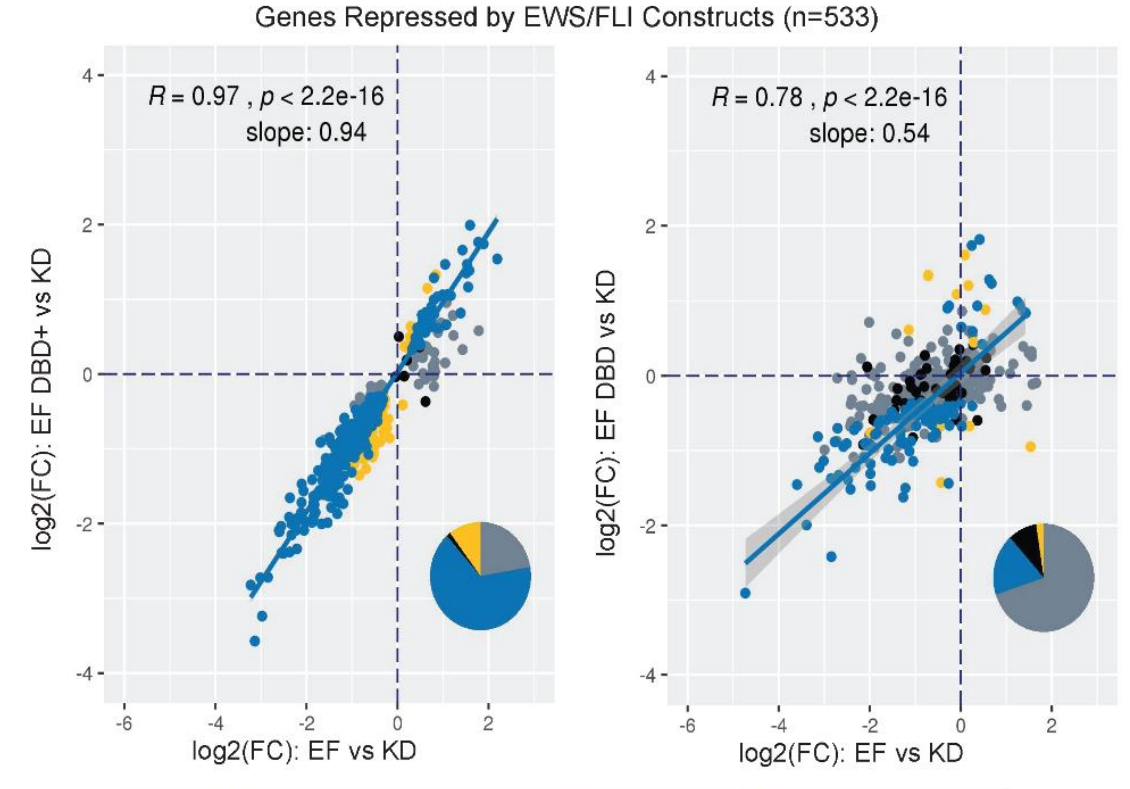
transcriptional regulation. a gene set activated by EF $(\log 2(F C)>1.5$, FDR $<0.05)$ or $(B)$ a gene set repressed by EF $(\log 2(\mathrm{FC})<-1.5$, FDR $<0.05)$. (C) Genes significantly repressed by endogenous EWS/FLI were defined using a previous RNA-sequencing dataset (47). Genes repressed by EF, EF DBD, and EF DBD+ were compared to this list of EWS/FLI-repressed genes. Scatterplots comparing genes repressed by exogenous EF (on the x-axis) to EF DBD+ (left) or EF DBD (right) (on the y-axis) were plotted to determine the ability of these constructs to rescue repression of these genes. Significance was defined by a $\log 2(\mathrm{FC})<0$ and an adjusted $\mathrm{p}$-value $<0.05$. Pearson correlation coefficient and associated $p$-values with slope are noted on the plots. Pie charts represent the proportion of genes found in each of the described groups is also depicted. 
A

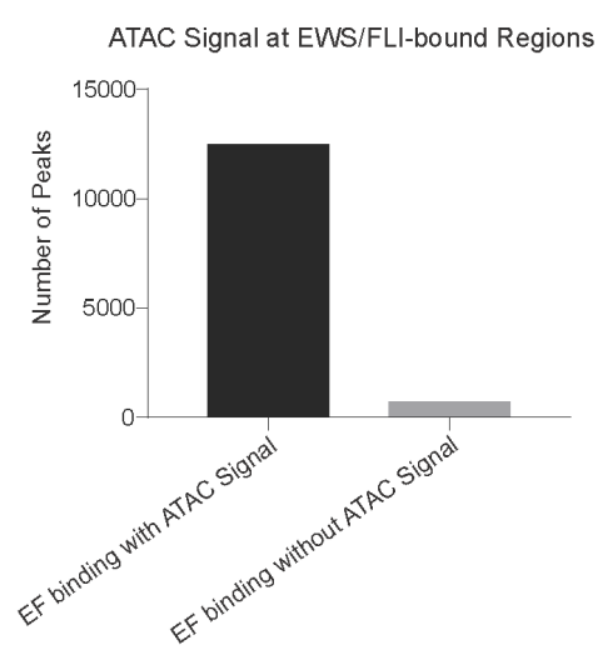

B
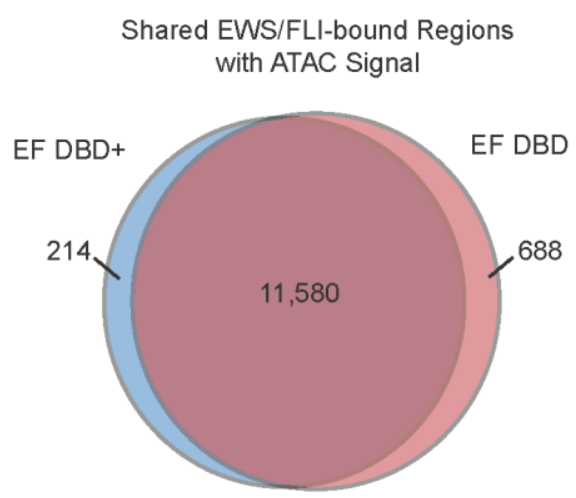

C

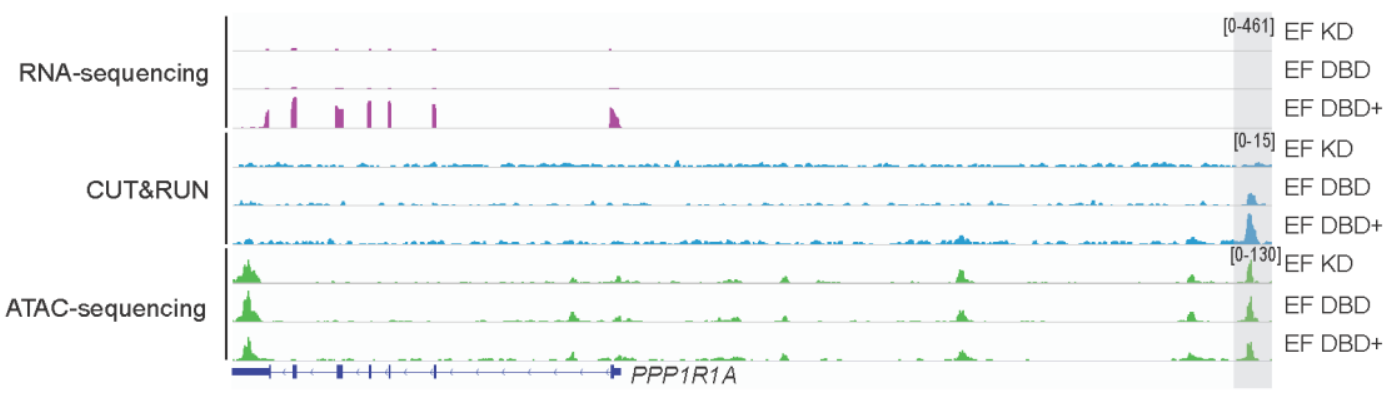

D

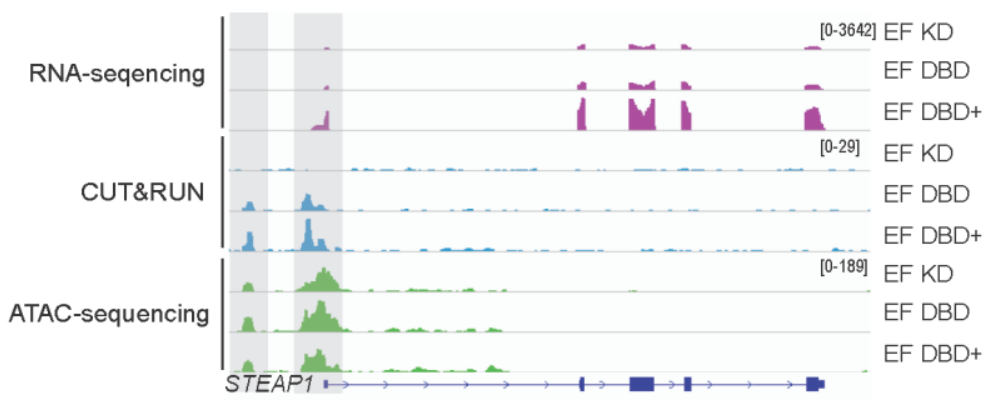

Figure 5. Chromatin-opening ability of EWS/FLI is unaltered by deletions flanking the FLI DNA-binding domain.

(A) All EWS/FLI-bound loci in A673 cells (determined by CUT\&RUN of knock-down/rescue cells expressing full-length EWS/FLI [EF]) were compared to loci harboring ATAC signal peaks and shown in graphical format. There were 12,482 EF-bound peaks with ATAC signal and 696 EFbound peaks without ATAC signal. (B) Venn diagram analysis of regions bound by EF DBD+ and/or EF DBD that also had overlapping ATAC signals. (C-D) Representative tracks of RNAsequencing, CUT\&RUN genomic localization, and ATAC-sequencing signals for the indicated knock-down/rescue A673 cells (EF KD = iEF + EF; EF DBD = iEF + EF DBD; EF DBD+ = iEF + EF DBD+). Scales to view tracks were kept consistent across sequencing type in each panel and are represented on the right. Representative genes $P P P 1 R 1 A(C)$ and STEAP1 (D) are regulated 
bioRxiv preprint doi: https://doi.org/10.1101/2020.10.29.355859; this version posted October 30, 2020. The copyright holder for this preprint (which was not certified by peer review) is the author/funder, who has granted bioRxiv a license to display the preprint in perpetuity. It is made available under aCC-BY-NC 4.0 International license.

923 by EF DBD+ but not EF DBD (adjusted $p$-value $<0.05$ ) and overlapping CUT\&RUN and ATAC924 sequencing peaks are highlighted.

925

926

927

928

929

930

931

932

933

934

935

936

937

938

939

940

941

942

943

944

945

946

947

948

949

950

951

952

953

954

955

956

957

958

959

960

961

962

963

964

965

966

967

968

969

970

971

972

973 
bioRxiv preprint doi: https://doi.org/10.1101/2020.10.29.355859; this version posted October 30, 2020. The copyright holder for this preprint (which was not certified by peer review) is the author/funder, who has granted bioRxiv a license to display the preprint in perpetuity. It is made available under aCC-BY-NC 4.0 International license.

A

EWS/FLI-mediated Activated Genes

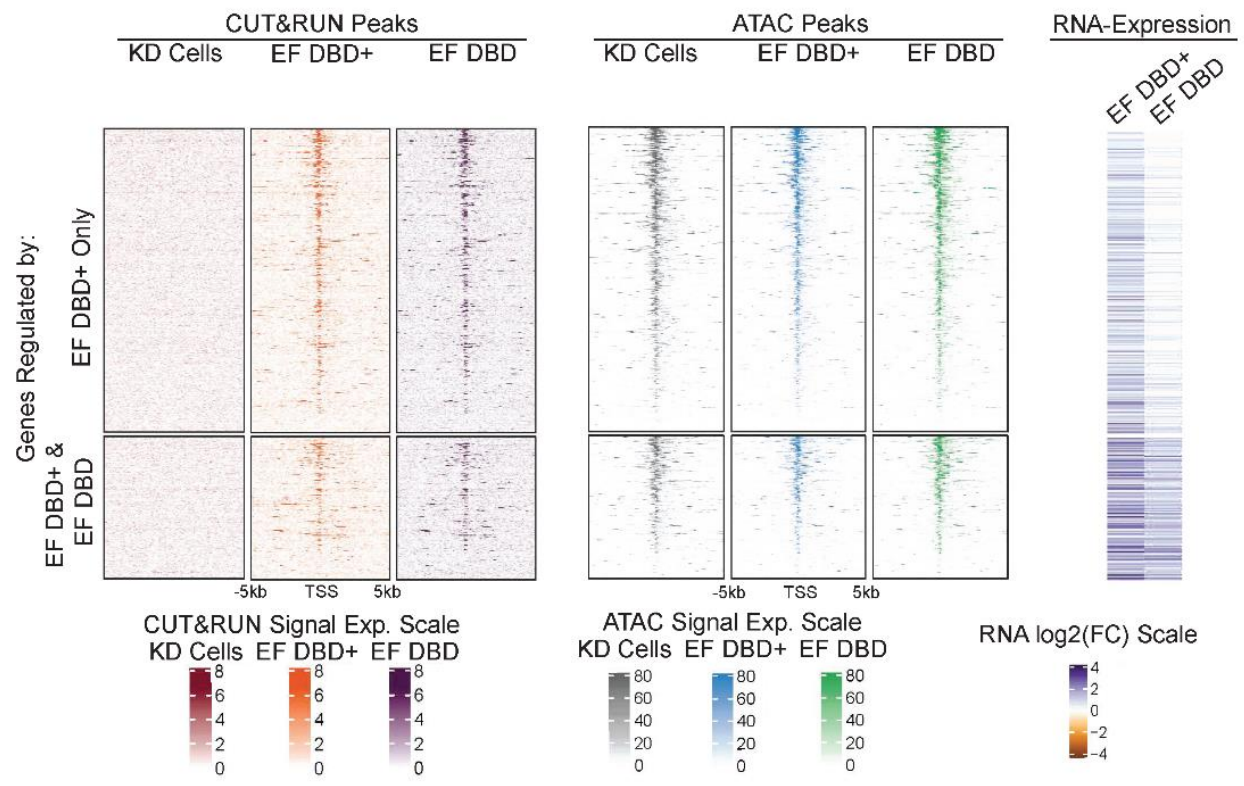

B

EWS/FLI-mediated Repressed Genes
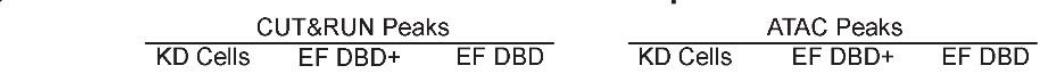

$\underline{\text { RNA-Expression }}$
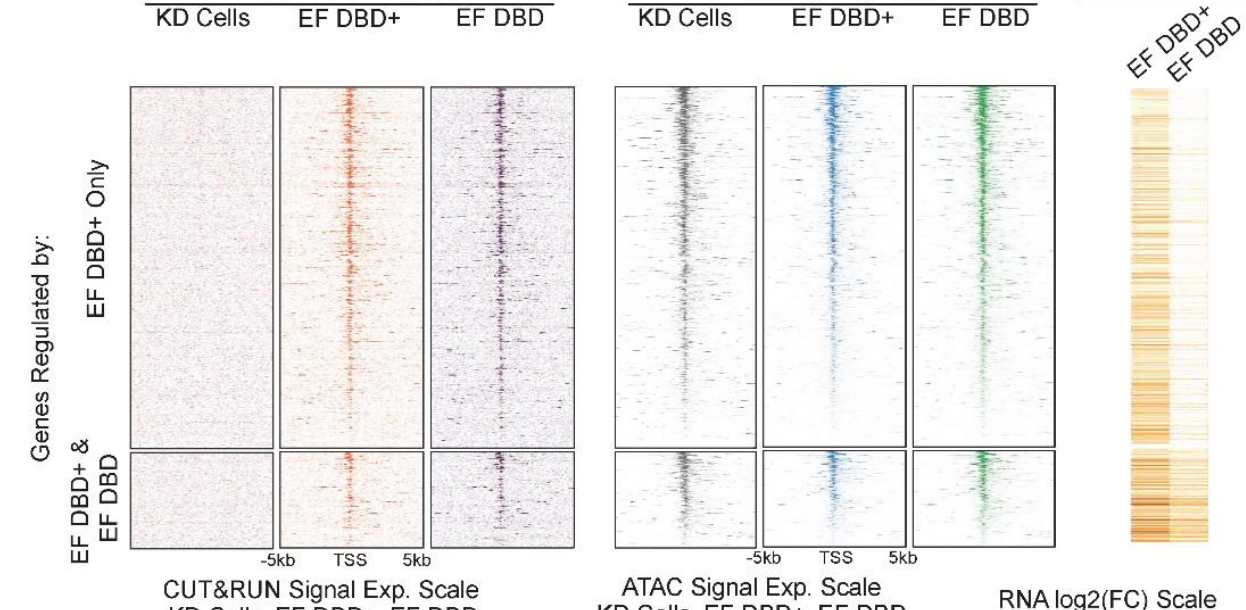

\section{Supplemental Figure 4. Heatmap analysis of ATAC-signal at EWS/FLI-mutant bound} activated and repressed genes.

(A-B) Heatmaps depicting CUT\&RUN and ATAC-sequencing signals, centered on the nearest transcriptional start sites (TSS) of genes regulated by EF DBD+ only or both EF DBD+ and EF DBD. EWS/FLI-mediated activated genes are visualized in (A) and repressed genes in (B). Knock-down cells (KD; iEF + Empty Vector), EF DBD+ (iEF + EF DBD+), and EF DBD (iEF + EF DBD) were compared (scales for peak height are depicted below heatmaps). The log2(FC) of RNA expression for EF DBD+ and EF DBD (compared to KD) is pictured on the right with $\log 2(\mathrm{FC})$ scale depicted below. 
A

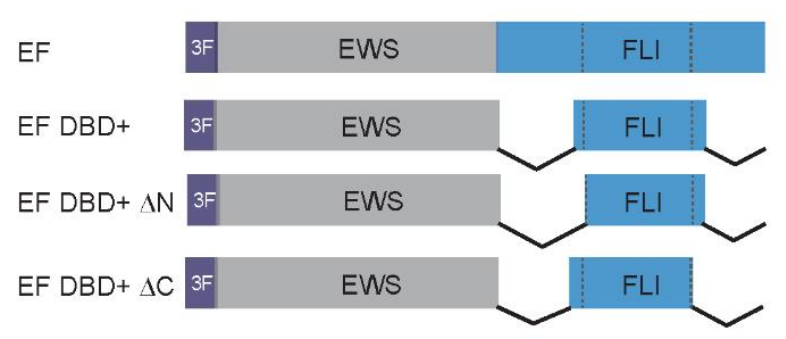

C

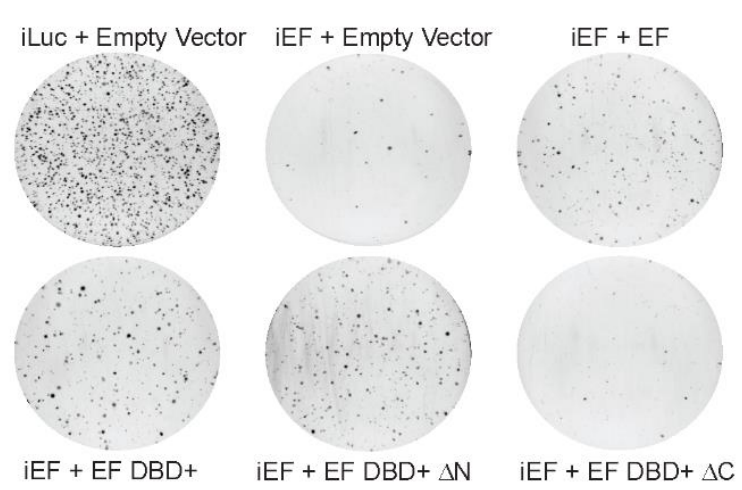

B

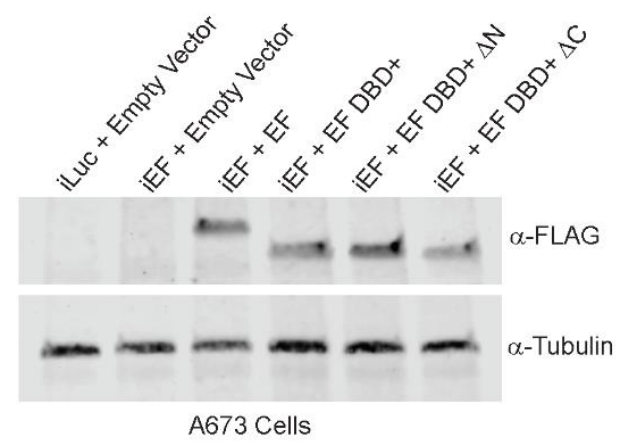

D

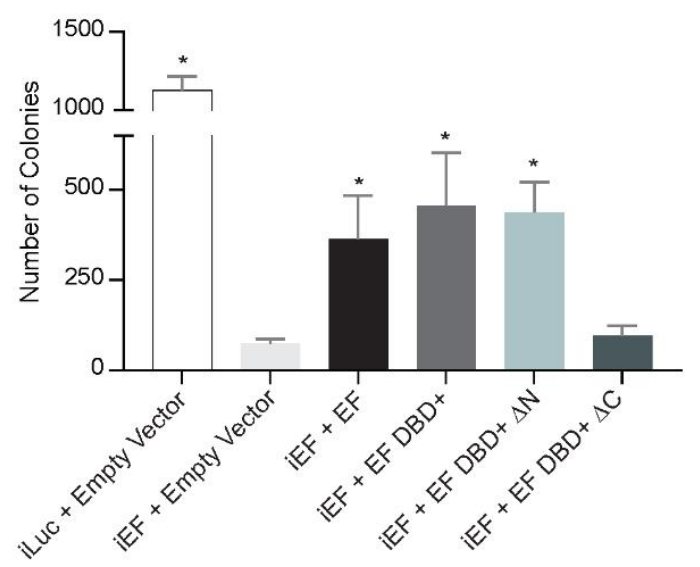

Figure 6. The carboxyl-terminal amino acids flanking the FLI DNA-binding domain are essential for EWS/FLI-mediated oncogenic transformation.

(A) Protein schematics of 3xFLAG-tagged (3F) EWS/FLI constructs: EF represents a full-length EWS/FLI; EF DBD+ $\triangle N$ represents EWS/FLI containing the DBD+ version of FLI missing the 7amino-terminal amino acids to the DBD; EF DBD $+\triangle \mathrm{C}$ represents EWS/FLI containing the DBD+ version of FLI missing the 10 carboxyl-terminal amino acids to the DBD. (B) Western blots of constructs expressed in A673 cells using our knock-down/rescue system. (C) Representative soft agar assay results are depicted for each of the indicated constructs. (D) Soft agar assay colony formation quantification. Data represented by mean \pm SEM $(n=3$ independent replicates). Statistical significance of samples when compared to iEF + Empty Vector was used to determine the ability of each version of EWS/FLI to mediate oncogenic transformation in A673 cells. Asterisks indicate $p$-value $<0.05$ as compared to negative control iEF + Empty Vector sample with no EWS/FLI expression. 
A

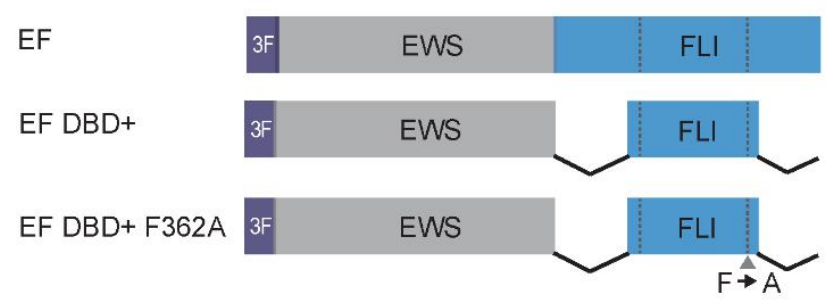

C

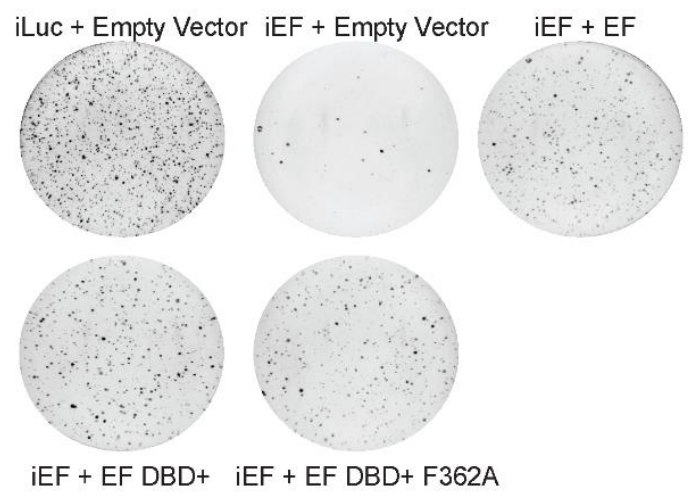

B

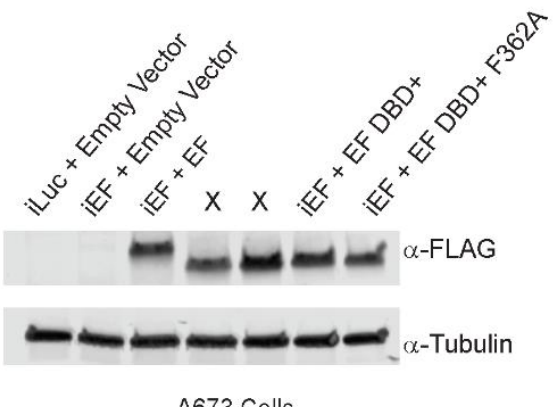

D

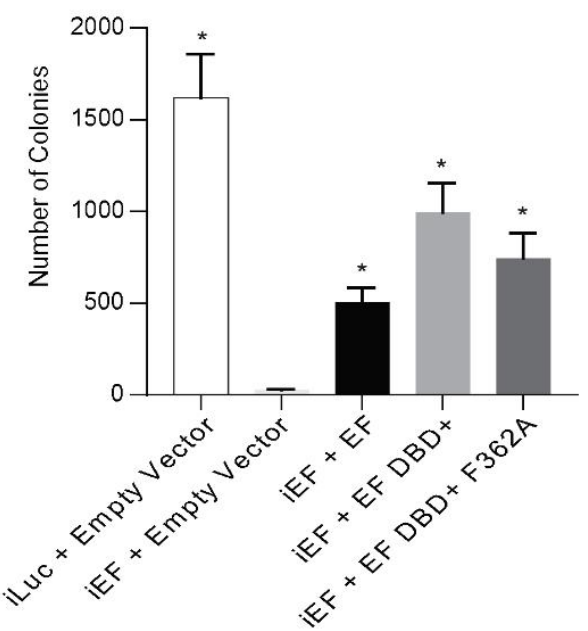

\section{Supplemental Figure 5. Homodimerization motif is dispensable for EWS/FLI-mediated oncogenic transformation.}

(A) Protein schematics of 3xFLAG-tagged (3F) EWS/FLI constructs: EF represents full-length EWS/FLI; EF DBD+ contains EWS fused to the DBD+ version of FLI; EF DBD+ F362A represents EWS fused to the DBD+ version of FLI with the phenylalanine "F" residue at residue 362 mutated to alanine "A". (B) Constructs were expressed in A673 cells using our knock-down/rescue system and Western blot analysis was used to determine efficient expression of these proteins using $\alpha$ FLAG antibody for detection of EWS/FLI constructs and $\alpha$-Tubulin as a loading control. (Samples labeled as $X$ are not relevant to this current set of experiments.) (C) Representative soft agar assay results are depicted, including controls and experimental samples. (D) Soft agar assay colony formation quantification. Data is represented by mean \pm SEM $(n=3$ independent replicates). Asterisks indicate $p$-value $<0.005$ as compared to samples with EWS/FLI knock-down (iEF + Empty Vector). 
Additional file 1. Amino acids references for EWS/FLI Mutant Constructs

\begin{tabular}{|l|l|l|l|}
\hline & \multicolumn{3}{|c|}{ Amino acids residues according to protein: } \\
\hline Construct Name & $\begin{array}{l}\text { EWSR1 } \\
\text { (NP_001156757.1) }\end{array}$ & $\begin{array}{l}\text { FLI1 } \\
\text { (NP_002008.2) }\end{array}$ & $\begin{array}{l}\text { "Type IV" EWS/FLI } \\
\text { (May et al., 1993) }\end{array}$ \\
\hline Full-length “Type IV" EF & $1-265$ & $242-452$ & $266-476$ \\
\hline EF $\Delta$ N-FLI & $1-265$ & $275-452$ & $299-476$ \\
\hline EF $\Delta$ C-FLI & $1-265$ & $242-373$ & $266-397$ \\
\hline EF DBD & $1-265$ & $277-361$ & $302-386$ \\
\hline EF DBD+ & $1-265$ & $270-371$ & $295-396$ \\
\hline FLI DBD & - & $277-361$ & $302-386$ \\
\hline FLI DBD+ & - & $270-371$ & $295-396$ \\
\hline EF DBD+ $\Delta N$ & $1-265$ & $277-371$ & $302-396$ \\
\hline EF DBD+ $\Delta C$ & $1-265$ & $270-361$ & $295-386$ \\
\hline EF DBD+ F362A & $1-265$ & $270-371$, F362A & $295-396$, F362A \\
\hline
\end{tabular}


Additional file 2. Sequences for primers used in RT-qPCR experiments

\begin{tabular}{|c|c|c|}
\hline Gene & Forward Primer & Reverse Primer \\
\hline EWS/FLI & 5'-CAGTCACTGCACCTCCATCC & 5'-TTCATGTTATTGCCCCAAGC \\
\hline RPL30 & 5'-GGGGTACAAGCAGACTCTGAAG & 5'-ATGGACACCAGTTTTAGCCAAC \\
\hline
\end{tabular}

1068

1069

1070

1071

1072

1073

1074

1075

1076

1077

1078

1079

1080

1081

1082

1083

1084

1085

1086

1087

1088

1089

1090

1091

1092

1093

1094

1095

1096

1097

1098

1099

1100

1101

1102

1103

1104

1105

1106 
bioRxiv preprint doi: https://doi.org/10.1101/2020.10.29.355859; this version posted October 30, 2020. The copyright holder for this preprint (which was not certified by peer review) is the author/funder, who has granted bioRxiv a license to display the preprint in perpetuity. It is made available under aCC-BY-NC 4.0 International license.

Additional file 3. Fluorescein-labelled DNA-duplex oligonucleotides used for fluorescence anisotropy experiments

\begin{tabular}{|c|l|}
\hline DNA Duplex & \multicolumn{1}{|c|}{ Sequence (forward strand of duplex) } \\
\hline $\begin{array}{c}\text { High Affinity } \\
\text { (HA) Site }\end{array}$ & /56FAM/TTTACCGGAAGTTT \\
\hline 2X GGAA & /56FAM/TTTGGAAGGAATTT \\
\hline 20X GGAA & $\begin{array}{l}\text { /56FAM/ } \\
\text { TTTGGAAGGAAGGAAGGAAGGAAGGAAGGAAGGAAGGAAGGAAGGAAGGA } \\
\text { AGGAAGAAGGAAGGAAGGAAGGAGGAAGGATTT }\end{array}$ \\
\hline
\end{tabular}

